\title{
Store-Operated Calcium Channels: New Perspectives on Mechanism and Function
}

\author{
Richard S. Lewis \\ Department of Molecular and Cellular Physiology, Stanford University School of Medicine, Stanford, \\ California 94305 \\ Correspondence: rslewis@stanford.edu
}

\begin{abstract}
Store-operated calcium channels (SOCs) are a nearly ubiquitous $\mathrm{Ca}^{2+}$ entry pathway stimulated by numerous cell surface receptors via the reduction of $\mathrm{Ca}^{2+}$ concentration in the ER. The discovery of STIM proteins as ER $\mathrm{Ca}^{2+}$ sensors and Orai proteins as structural components of the $\mathrm{Ca}^{2+}$ release-activated $\mathrm{Ca}^{2+}$ (CRAC) channel, a prototypic SOC, opened the floodgates for exploring the molecular mechanism of this pathway and its functions. This review focuses on recent advances made possible by the use of STIM and Orai as molecular tools. I will describe our current understanding of the store-operated $\mathrm{Ca}^{2+}$ entry mechanism and its emerging roles in physiology and disease, areas of uncertainty in which further progress is needed, and recent findings that are opening new directions for research in this rapidly growing field.
\end{abstract}

$\mathrm{C}$ alcium is a remarkably multifunctional signaling ion, at the heart of diverse biological processes that direct the birth, development, function, and eventual death of cells, tissues, and organisms. Cells use a diverse array of transporters and channels to regulate intracellular $\mathrm{Ca}^{2+}$ concentration $\left(\left[\mathrm{Ca}^{2+}\right]_{\mathrm{i}}\right)$. A major pathway present in nearly all metazoan cells is the store-operated $\mathrm{Ca}^{2+}$ channel (SOC). The defining feature of SOCs, the one that distinguishes them from all other classes of $\mathrm{Ca}^{2+}$ channels discussed in this volume, is their activation by the reduction of $\mathrm{Ca}^{2+}$ concentration in the lumen of the ER $\left(\left[\mathrm{Ca}^{2+}\right]_{\mathrm{ER}}\right)$. Though they were originally described in nonexcitable cells (cells lacking the ability to fire action potentials), they are now known to be present in virtually all cells, including excitable cells like skeletal muscle and neurons (Parekh and Putney 2005).

Physiologically, SOCs are most commonly activated by stimuli that release $\mathrm{Ca}^{2+}$ from the ER. This generally involves receptors that activate phospholipase $\mathrm{C}$ to produce inositol 1,4,5-trisphosphate $\left(\mathrm{IP}_{3}\right)$ and activate $\mathrm{IP}_{3}$ receptors in the ER, but can also result from $\mathrm{Ca}^{2+}$-induced $\mathrm{Ca}^{2+}$ release through ER/SR ryanodine receptors. The notion that $\mathrm{ER} \mathrm{Ca}^{2+}$ depletion can control $\mathrm{Ca}^{2+}$ entry was first formulated by Jim Putney 25 years ago as the "capacitative calcium entry" hypothesis based on observations that $\mathrm{Ca}^{2+}$ entry triggered by muscarinic agonists was more closely linked to the emptiness of the ER store than to $\mathrm{IP}_{3}$ elevation or occupation of the muscarinic receptor (Putney 1986). The introduction of thapsigargin

Editors: Martin Bootman, Michael J. Berridge, James W. Putney, and H. Llewelyn Roderick

Additional Perspectives on Calcium Signaling available at www.cshperspectives.org

Copyright (C) 2011 Cold Spring Harbor Laboratory Press; all rights reserved; doi: 10.1101/cshperspect.a003970

Cite this article as Cold Spring Harb Perspect Biol 2011;3:a003970 


\section{R.S. Lewis}

(TG) (Thastrup et al. 1989), a sarcoendoplasmic reticulum $\mathrm{Ca}^{2+}$-ATPase (SERCA) inhibitor that depletes $\mathrm{ER} \mathrm{Ca}^{2+}$ independently of receptors and $\mathrm{IP}_{3}$, and methods for measuring $\left[\mathrm{Ca}^{2+}\right]_{\mathrm{i}}$ in single cells (fura-2, indo-1, etc.) (Grynkiewicz et al. 1985) provided powerful tools that greatly accelerated progress in establishing store-operated $\mathrm{Ca}^{2+}$ entry (SOCE, as it was later renamed) as a ubiquitous $\mathrm{Ca}^{2+}$ entry pathway. TG-induced $\mathrm{Ca}^{2+}$ entry was soon shown to occur in dozens of cell types (Putney and Bird 1993; Parekh and Penner 1997), though nothing was known about the diversity of pathways that might be involved, let alone their molecular basis.

A major step forward was the identification of store-operated $\mathrm{Ca}^{2+}$ currents in mast cells and $\mathrm{T}$ cells. This achievement arose initially from attempts to identify $\mathrm{Ca}^{2+}$ conductances triggered by secretory agonists in mast cells and antigen receptors in $\mathrm{T}$ cells (Penner et al. 1988; Lewis and Cahalan 1989). In both cases, extremely small currents were detected and linked to large $\left[\mathrm{Ca}^{2+}\right]_{\mathrm{i}}$ rises, suggesting a high $\mathrm{Ca}^{2+}$ selectivity. In $\mathrm{T}$ cells, the current was shown to activate spontaneously during wholecell recordings and in response to the $\mathrm{T}$-cell mitogen phytohemagglutinin in perforatedpatch recordings (Lewis and Cahalan 1989). Soon after, fluorescence-based studies showed that $\mathrm{Ca}^{2+}$ influx triggered through $\mathrm{T}$ cell mitogens shared several features with TG-induced influx, suggesting that $\mathrm{T}$ cell receptor agonists activated the store-dependent pathway (Mason et al. 1991; Sarkadi et al. 1991). These two paths of research converged when Hoth and Penner described a highly $\mathrm{Ca}^{2+}$-selective current in mast cells that was activated in whole-cell recordings spontaneously (by $\mathrm{Ca}^{2+}$ chelators), by $\mathrm{IP}_{3}$, and by ionomycin, and called it the $\mathrm{Ca}^{2+}$ release-activated $\mathrm{Ca}^{2+}$ (CRAC) current (Hoth and Penner 1992). In Jurkat $\mathrm{T}$ cells, Zweifach and Lewis showed that TG activated a similar current, which appeared to be identical to the mitogen-stimulated current described earlier, and made the first estimate of its characteristically tiny conductance $(\sim 20$ femtosiemens, far too small to resolve single-channel currents) (Zweifach and Lewis 1993). These initial studies defined a membrane conductance that over the next decade would be described biophysically and pharmacologically in detail, providing a characteristic "fingerprint" culled from its ion selectivity, unitary conductance, and regulation by intra- and extracellular $\mathrm{Ca}^{2+}$ and pharmacological inhibitors (Parekh and Penner 1997; Prakriya et al. 2004).

Among several currents that were described as store-operated in different cells, the CRAC current emerged as the prototype because of its extensive characterization and the weight of evidence showing that it could be activated by $\mathrm{ER} \mathrm{Ca}^{2+}$ depletion independently of surface receptors or changes in cytosolic $\left[\mathrm{Ca}^{2+}\right]$. This included activation by intracellular $\mathrm{Ca}^{2+}$ chelators, SERCA inhibitors or ionomycin at constant intracellular $\left[\mathrm{Ca}^{2+}\right]_{\mathrm{i}}$, and by the $\mathrm{Ca}^{2+}$ chelator TPEN loaded into the ER (Prakriya et al. 2004; Parekh and Putney 2005). In fact, the CRAC channel is the only store-operated channel whose input-output relation is known. This relation, first examined by Hofer et al. (1998) and later quantified by Luik et al. (2008) using an ER-targeted cameleon protein, shows that $\mathrm{I}_{\mathrm{CRAC}}$ is a highly nonlinear function of $\left[\mathrm{Ca}^{2+}\right]_{\mathrm{ER}}$, with a Hill coefficient of $\sim 4$ and a $\mathrm{K}_{1 / 2}$ of $170 \mu \mathrm{M}$. Given a resting $\left[\mathrm{Ca}^{2+}\right]_{\mathrm{ER}}$ of $\sim 400 \mu \mathrm{M}$, these results suggest that the ER must be depleted by $\sim 25 \%$ before $\mathrm{I}_{\mathrm{CRAC}}$ begins to activate significantly.

Over the two decades after Putney formalized the capacitative $\mathrm{Ca}^{2+}$ entry hypothesis, many mechanisms were proposed as the link between $\mathrm{Ca}^{2+}$ store depletion and SOCE. Among these, diffusible messengers released from the $\mathrm{ER}$, insertion of CRAC channels into the plasma membrane, and conformational coupling of CRAC channels with $\mathrm{IP}_{3}$ receptors in the ER were the most extensively studied, but in the absence of molecular substrates were difficult to establish (Prakriya et al. 2004; Parekh and Putney 2005). The CRAC channel fingerprint proved useful in ruling out a number of candidate genes for the CRAC channel itself, particularly members of the transient receptor potential (TRP) protein family, but its identity remained a mystery (Prakriya et al. 2004; Parekh and Putney 2005). The discoveries of the ER 
$\mathrm{Ca}^{2+}$ sensor STIM1 in 2005 and the CRAC channel protein Orail a year later marked an unmistakable turning point in the field, as they provided the first and most essential molecular tools with which to dissect the SOCE mechanism. The history of these discoveries and the early revelations they afforded have been reviewed extensively (Cahalan et al. 2007; Wu et al. 2007; Fahrner et al. 2009; Putney 2009; Várnai et al. 2009; Hogan et al. 2010). In this review, I will summarize our current understanding of how $\mathrm{Ca}^{2+}$ store depletion leads to $\mathrm{Ca}^{2+}$ entry at a molecular level, and the role of STIM oligomerization and additional proteins in this process. I will also describe how these discoveries and the ensuing studies have increased awareness of SOCE roles in physiology and disease, and have created entirely new directions for research. Throughout I will emphasize work on STIM1 and Orail mainly because they have been the most extensively studied isoforms, but will discuss other STIM and Orai isoforms to highlight important functional differences. For more information on these other isoforms, the reader is referred to the reviews cited above.

\section{STIM AND ORAI: A MOLECULAR BASIS FOR STORE-OPERATED CALCIUM ENTRY}

RNAi screens for inhibitors of SOCE led to identification of the STIM protein family. Using small-scale RNAi screens Roos et al. (2005) identified STIM in Drosophila S2 cells and by homology the mammalian homologs STIM1 and STIM2, while Liou et al. (2005) identified STIM1 and STIM2 in a HeLa cell screen. Shortly thereafter, the Rao, Kinet, and Cahalan groups identified the Orai/CRACM protein family (Orai/CRACM1, 2, and 3) by genome-wide RNAi screens in S2 cells for inhibition of SOCE (Vig et al. 2006b; Zhang et al. 2006) or of NFAT translocation combined with linkage analysis of a family in which a loss of CRAC channel function led to severe combined immunodeficiency (SCID) (Feske et al. 2006).

STIM1 was quickly identified as a $\mathrm{Ca}^{2+}$ sensor for SOCE because it displayed an EF-handlike sequence on the predicted luminal side, and neutralization of acidic residues to reduce $\mathrm{Ca}^{2+}$ binding by the EF hand elicited constitutive $\mathrm{Ca}^{2+}$ entry independent of store depletion, in effect mimicking the store-depleted state (Liou et al. 2005; Zhang et al. 2005). Of the three Orai isoforms in mammals, Orail was most closely connected to the CRAC channel because a point mutation (R91W) in Orail led to a complete loss of $\mathrm{I}_{\mathrm{CRAC}}$ in human $\mathrm{T}$ cells (Feske et al. 2005, 2006), Orail is the predominant isoform in these cells, and its properties (fast $\mathrm{Ca}^{2+}$-dependent inactivation, sensitivity to 2aminoethyldiphenyl borate (2-APB), and predominant expression in human $\mathrm{T}$ cells) most closely match those of CRAC (Lis et al. 2007). Orail was shown to be the pore-forming subunit of the CRAC channel by changes in $\mathrm{I}_{\mathrm{CRAC}}$ calcium selectivity caused by mutating highly conserved glutamates (particularly E106D) in the trans-membrane domains (Prakriya et al. 2006; Vig et al. 2006a; Yeromin et al. 2006).

\section{The Molecular Choreography of SOCE}

Depletion of $\mathrm{ER} \mathrm{Ca}^{2+}$ stores activates SOCE through a distinctive rearrangement of STIM1 and Orail in the cell. At resting levels of $\left[\mathrm{Ca}^{2+}\right]_{\mathrm{ER}}(\sim 400-500 \mu \mathrm{M})$, STIM1 and Orail are both mobile proteins that are relatively diffusely localized throughout the ER and plasma membranes, respectively (Fig. 1A). Within seconds, store depletion causes STIM1 to accumulate at the cell periphery, forming "puncta" in confocal or total internal reflection fluorescence (TIRF) microscopic images of cells expressing fluorescently labeled STIM1 (Liou et al. 2005; Zhang et al. 2005). These peripheral puncta correspond at the ultrastructural level to specialized regions of smooth ER positioned within $\sim 10-20 \mathrm{~nm}$ of the plasma membrane, known as ER-PM junctions (Fig. 1B) (Wu et al. 2006; Lur et al. 2009; Orci et al. 2009). In Jurkat T cells expressing ER-targeted horseradish peroxidase, electron microscopic studies show that native ER-PM junctions cover $<5 \%$ of the cell surface (Wu et al. 2006). Over roughly the same time period, Orail accumulates at PM sites directly opposite STIM1 (Luik et al. 2006; Xu et al. 2006), where STIM1 binds to Orail and opens the CRAC channel, generating highly localized 


\section{R.S. Lewis}

A

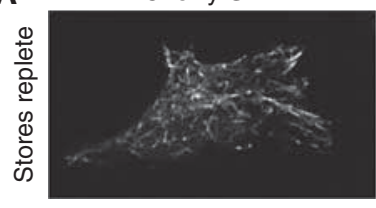

$\downarrow$

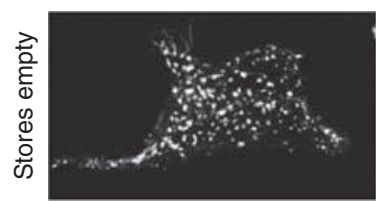

eGFP-Orai1

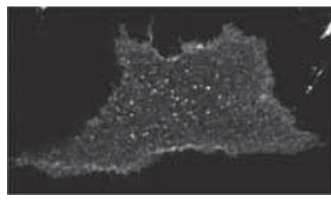

$\downarrow$

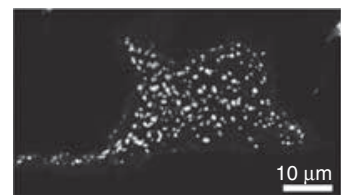

B

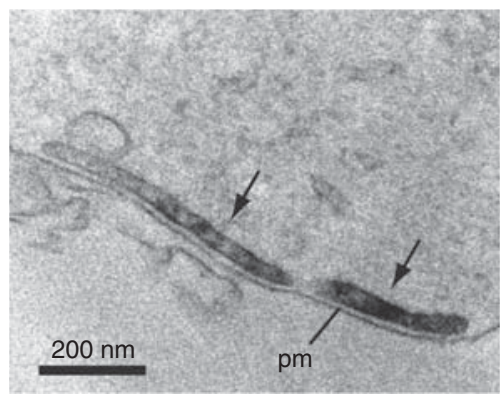

C

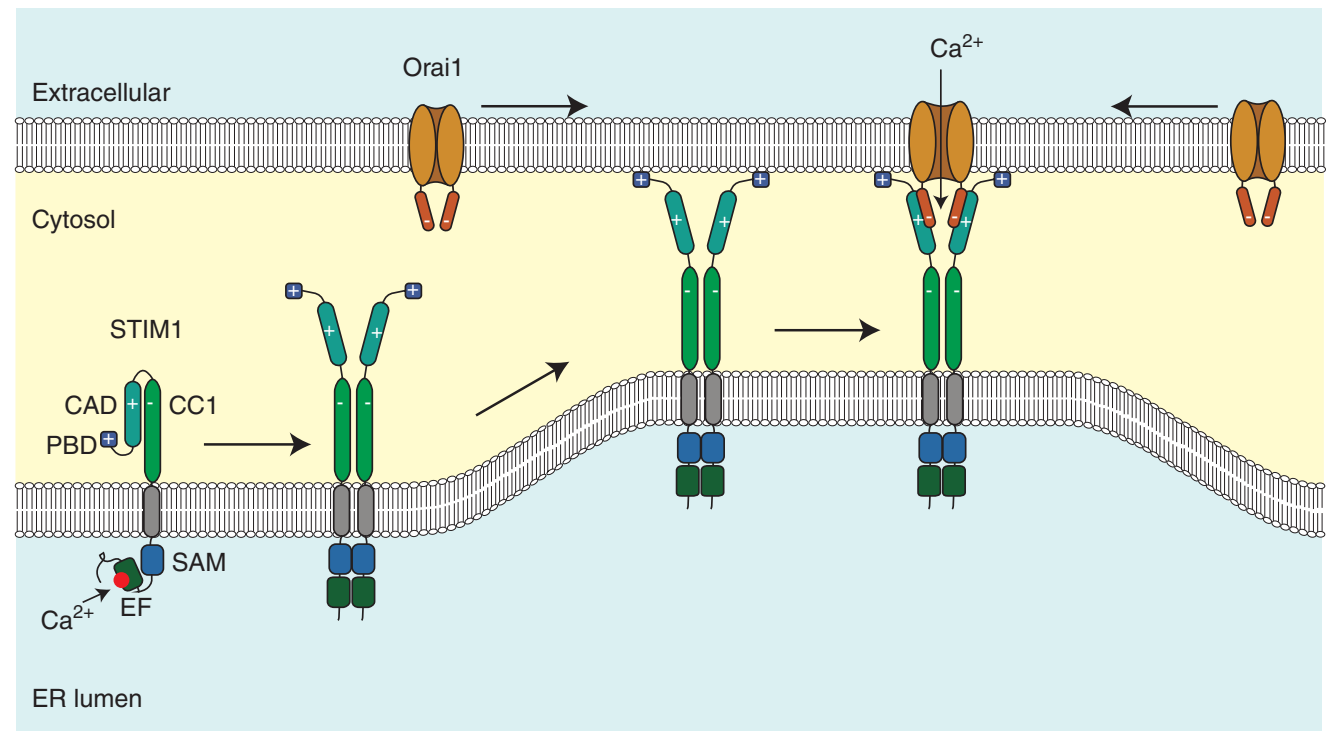

Figure 1. The molecular choreography of store-operated calcium entry. (A) In this resting HEK 293 cell, mCherry-STIM1 is localized throughout the ER and eGFP-Orail is dispersed throughout the PM of the cell footprint. Following store depletion, both proteins redistribute into colocalized puncta. (Panel A is from Park et al. (2009) and reprinted with permission from Elsevier (C) 2009.) (B) Electron micrograph showing accumulation of HRP-STIM1 in the ER (arrows) at ER-PM junctions in a Jurkat T cell after store depletion. (Panel B is modified from Luik et al. (2006) and reprinted with permission from The Rockefeller University Press (C) 2006.) (C) A current model for SOCE, divided into four phases from left to right. For simplicity and to emphasize the interactions of STIM1 and Orail, full stoichiometries are not shown (STIM1 is likely to be a dimer at rest and after store depletion at least a tetramer, and 8 STIM1s probably interact with each CRAC channel for full activation). At far left, STIM1 is pictured in its resting state when $\mathrm{Ca}^{2+}$ stores are replete. The $\mathrm{Ca}^{2+}$-bound EF hand interacts with the SAM domain, and electrostatic interactions between acidic residues in CC1 ( - ) and basic residues in CAD $(+)$ prevent CAD from interacting with Orai. On store depletion, $\mathrm{Ca}^{2+}$ is released from the EF hand, allowing STIM1 to oligomerize (shown here schematically as a dimer) and assume an extended conformation that exposes CAD and the polybasic domain. Oligomers move to ER-PM junctions by diffusion in the ER membrane, and accumulate there through interaction of the polybasic domain with phosphoinositides in the PM. At the junction, CRAC channels diffusing in the PM bind to the STIM1 CAD via electrostatic interaction of a coiled-coil region of the Orail carboxyl terminus $(-)$ with basic CAD residues $(+)$. This interaction traps CRAC channels and combined with CAD interactions with the Orail amino terminus (not shown) opens them at the ER-PM junction. EF, canonical EF hand; SAM, sterile $\alpha$-motif; CC1, coiled-coil 1; CAD, CRAC activation domain; $\mathrm{PBD}$, polybasic domain. 
$\mathrm{Ca}^{2+}$ "hot spots" visible by TIRF microscopy (Luik et al. 2006). Puncta formation is reversible; store refilling causes both proteins to slowly disperse from the junctions and revert to their diffuse localization (Liou et al. 2005; Várnai et al. 2007; Malli et al. 2008; Smyth et al. 2008).

The assembly of these elementary units of SOCE in response to store depletion is in most cells quite slow, occurring over seconds to tens of seconds, which largely reflects the time required for STIM1 and Orail to migrate to ER-PM junctions. The timing of these events may have physiologic consequence; for example, in T cells, the slow speed of CRAC complex assembly and disassembly may generate $\mathrm{Ca}^{2+}$ oscillations by creating lags between changes in $\left[\mathrm{Ca}^{2+}\right]_{\mathrm{ER}}$ and CRAC channel activity (Dolmetsch and Lewis 1994). However, activation of SOCE is not always so slow. Recent studies indicate that STIM1 in skeletal muscle is prelocalized to the triads where the sarcoplasmic reticulum comes to within $10 \mathrm{~nm}$ of the plasma membrane transverse tubule (Stiber et al. 2008). In these cells, SOCE can occur in $<1 \mathrm{sec}$ of $\mathrm{Ca}^{2+}$ release from the SR, and is thought to help replenish $\mathrm{SR} \mathrm{Ca}^{2+}$ during high-frequency stimulation (Edwards et al. 2010). Thus, differential targeting of STIM1 and Orail in the resting state may adjust the activation kinetics of SOCE over orders of magnitude as needed in different cells.

Studies of the SOCE mechanism have reached a point where many of the underlying events can be understood in terms of the interactions of specific domains in STIM1 and Orail (Figs. 2 and 3). Below I discuss the functional roles of these domains in carrying out the major steps of the SOCE mechanism, diagrammed in Fig. 1C.

\section{Oligomerization of STIM Is a Regulatory Switch for SOCE}

The oligomerization of STIM is key to the regulation of its function. Early work on the isolated EF hand/sterile- $\alpha$ motif (EF-SAM) domain from STIM1 showed that removal of $\mathrm{Ca}^{2+}$ caused it to transition from a monomer to dimers and oligomers, prompting Ikura and colleagues to suggest that oligomerization of the EF-SAM domains may be the trigger for SOCE (Stathopulos et al. 2006). Supporting

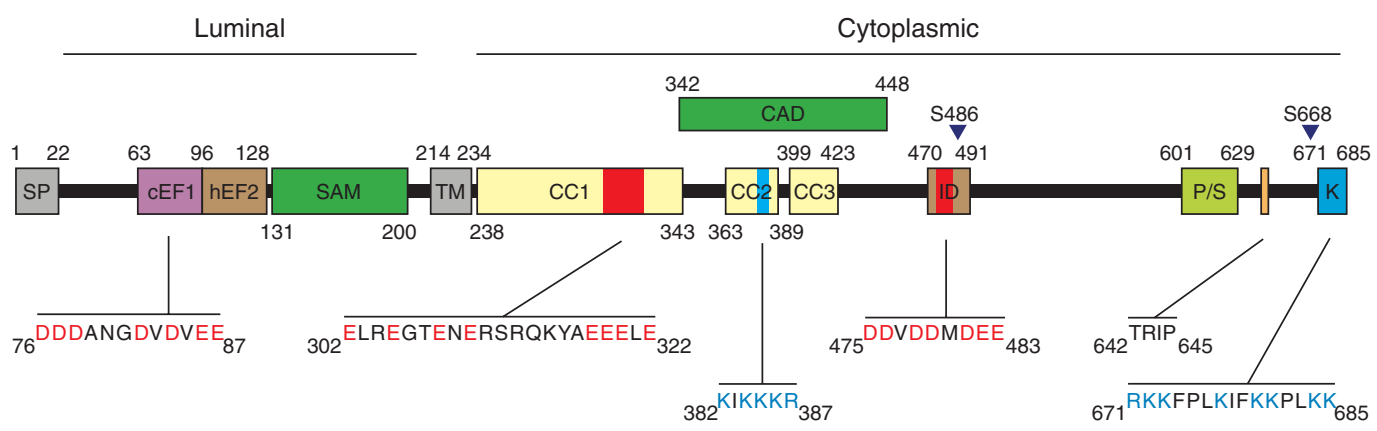

Figure 2. Functional organization of STIM1. The major functional domains of STIM1 are indicated by residue numbers relative to the translation initiation site. SP, signal peptide; cEF1, canonical EF hand; hEF2, hidden (noncanonical) EF hand; SAM, sterile $\alpha$-motif; TM, transmembrane domain; CC1-3, coiled-coil domains 1-3; CAD, CRAC activation domain; ID, inactivation domain; $\mathrm{P} / \mathrm{S}$, proline-serine-rich domain; $\mathrm{K}$, polybasic domain. CAD is highly similar to SOAR (aa 344-442) and Ccb9 (aa 339-444), not shown. Sequences are displayed for regions with established functions: the $\mathrm{Ca}^{2+}$ sensing domain in $\mathrm{CEF} 1$, the basic region of CC2 involved in autoinhibitory binding to the acidic region of $\mathrm{CC} 1$ and stimulatory binding to Orail, the acidic residues in the ID of STIM1 required for $\mathrm{Ca}^{2+}$-dependent inactivation, the EB1 binding sequence (TRIP) that links STIM1 to the tips of growing microtubules, and the carboxy-terminal polybasic domain that targets STIM1 to the ER-PM junction. Phosphorylation sites S486 and S668 help suppress STIM1 activity and SOCE during mitosis. Acidic and basic residues are shown in red and blue, respectively. 


\section{R.S. Lewis}

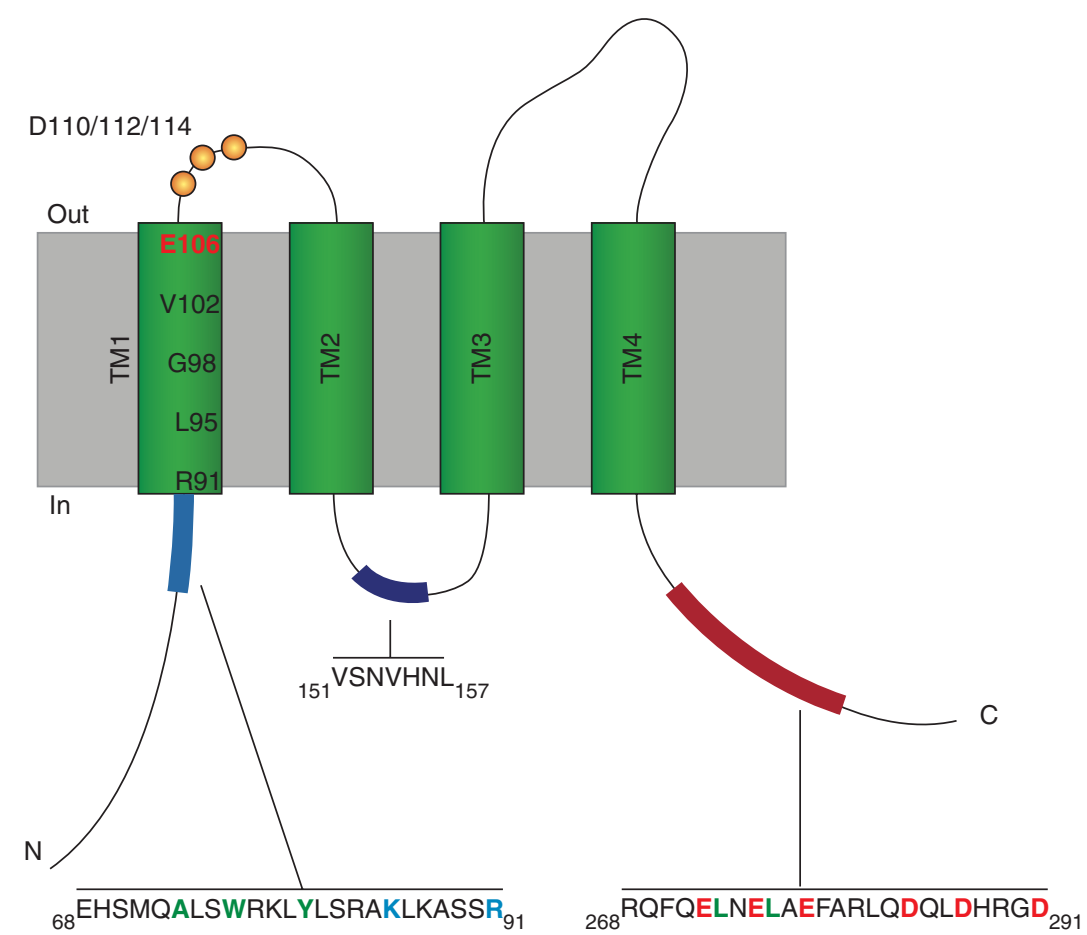

Figure 3. Functional organization of Orail. This schematic layout of a single Orail subunit includes the four transmembrane domains (TM1-TM4), amino and carboxyl termini, and the connecting loops. Functionally significant residues and sequences are shown. The indicated residues in TM1 line the aqueous pore, E106 (red) forms the ion selectivity filter, and R91 inhibits channel function when substituted by bulky hydrophobic residues. D110/112/114 help determine sensitivity to block by lanthanides. In the amino terminus proximal to the PM, residues 68-91 form a $\mathrm{Ca}^{2+} / \mathrm{CaM}$ binding domain, with residues essential for $\mathrm{CaM}$ binding and CDI indicated in bold green (A73, W76, Y80). This region also binds CAD and contains residues required for channel opening in bold blue (K85, R91). A domain in the intracellular loop is required for CDI, and a probable coiledcoil domain in the carboxyl terminus contains hydrophobic (bold green) and acidic (bold red) residues critical for binding STIM1 CAD.

this idea, its $\mathrm{Ca}^{2+}$ affinity of $0.2-0.6 \mathrm{mM}$ (Stathopulos et al. 2006) is similar to the $\left[\mathrm{Ca}^{2+}\right]_{\text {ER }}$ dependence of STIM1 translocation into puncta $\left(\mathrm{K}_{1 / 2} \sim 200 \mu \mathrm{M}\right)$ (Brandman et al. 2007; Luik et al. 2008). Importantly, increased Förster resonance energy transfer (FRET) between CFP- and YFP-labeled STIM1 after store depletion showed that STIM1 oligomerizes in cells after store depletion but prior to accumulation in puncta (Fig. 1C) (Liou et al. 2007; Malli et al. 2008; Muik et al. 2008). Subsequent NMR studies revealed a structural basis for this process. In the resting state, a single $\mathrm{Ca}^{2+}$ ion bound to the canonical EF hand exposes a hydrophobic cleft in STIM1 that interacts with hydrophobic anchor side chains from the SAM domain (Stathopulos et al. 2008). In this way, high $\left[\mathrm{Ca}^{2+}\right]_{\mathrm{ER}}$ prevents EF-SAM from engaging in intermolecular interactions, essentially providing a "brake" on spontaneous activation of SOCE. When $\mathrm{Ca}^{2+}$ is released from the EF hand (as during store depletion), hydrophobic regions are exposed, leading to oligomerization of the EF-SAM domains.

Although STIM1 and STIM2 are closely related in domain organization and show $>65 \%$ sequence similarity, STIM2 appears to have a lower affinity for $\mathrm{Ca}^{2+}$, such that it is partially $\mathrm{Ca}^{2+}$-free and localized to ER-PM junctions in resting cells (Brandman et al. 2007). 
The lower $\mathrm{Ca}^{2+}$ affinity of STIM2 may enable it to respond to smaller fluctuations of $\left[\mathrm{Ca}^{2+}\right]_{\mathrm{ER}}$, and by finely modulating SOCE act as a homeostatic regulator of cytosolic and $\mathrm{ER}\left[\mathrm{Ca}^{2+}\right]$ (Brandman et al. 2007). A reduced $\mathrm{Ca}^{2+}$ affinity may also enable STIM2 to play an active role in signaling, by sustaining a low level of $\mathrm{Ca}^{2+}$ entry through CRAC channels under conditions where stores have refilled enough to deactivate STIM1 (Oh-Hora et al. 2008). The full range of STIM2 functions is not yet understood.

The causal link between STIM1 oligomerization and SOCE was demonstrated by Luik et al. (2008), who replaced the EF-SAM domain of STIM1s with FRB or FKBP protein modules, and artificially cross-linked the modified STIM1 with a rapamycin analog. These conditions were sufficient to cause the modified STIM1s to accumulate in puncta and activate $\mathrm{I}_{\mathrm{CRAC}}$ independently of store depletion. Thus, the reorganization of STIM1 and Orail into colocalized complexes appears to be an autonomous process that is held in check simply by the state of oligomerization of STIM1.

Interestingly, in addition to structural changes in the EF-SAM domain, interactions of the cytoplasmic domains are also critical for the oligomerization of full-length STIM1 following store depletion. Although a truncated STIM1 containing only the EF-SAM domain attached to the TM domain dimerizes in the ER on store depletion, these dimers appear to be unstable (Covington et al. 2010). Addition of the cytosolic coiled-coil 1 (CC1) and CRAC activation domain (CAD) (Fig. 2, and described below) is necessary for the protein to form stable higher-order oligomers after store depletion. Knowing at a structural level how these domains interact will be central to understanding how structural changes in the EF-SAM domains are transmitted across the ER membrane to trigger the conformational changes in the cytosolic region of STIM1 that lead to its activation.

The conformational changes in STIM1 that occur in response to oligomerization have recently begun to come to light. Several complementary studies suggest that oligomerization causes the STIM1 cytoplasmic domain to unfold and unmasks a hidden activation domain. Balla and colleagues first noted that an acidic sequence in the Orail carboxyl terminus, thought to interact with a basic region in coiledcoil 2 (CC2) of STIM1 (K384-386) (Calloway et al. 2009, 2010), also resembles a region in CC1 of STIM1 (Korzeniowski et al. 2010). They hypothesized that the CC2 basic residues may engage this $\mathrm{CC} 1$ acidic domain in the resting state, creating an autoinhibitory clamp when stores are full (Figs. 1C and 2). Neutralizing the CC1 acidic domain led to spontaneous activation, whereas neutralizing the CC2 basic domain prevented interaction with Orail, supporting a model in which oligomerization destabilizes the intramolecular interaction, exposing CAD so that it can interact instead with the Orail carboxyl terminus. Intramolecular binding of the acidic and basic domains in STIM1 remains to be shown directly; however, concurrent studies of soluble STIM1 cytoplasmic fragments support the model. From a combination of FRET measurements and biophysical analysis, Muik et al. (2011) suggest that the cytoplasmic domain of STIM1 adopts a folded conformation at rest but elongates on binding to Orail. Mutations of hydrophobic residues in CC1, CC2, and coiled-coil 3 (CC3) appeared to elongate the STIM1 fragment in the absence of Orail, suggesting that coiled-coil formation in all three regions is involved in maintaining the resting folded conformation.

\section{Accumulation of STIM at ER-PM Junctions}

Two main mechanisms have been proposed to explain how STIM1 moves to ER-PM junctions. FRAP studies have suggested that STIM1 moves passively by diffusion with an estimated diffusion coefficient (D) of $0.1-0.15 \mu \mathrm{m}^{2} / \mathrm{s}$ in the ER membrane (Liou et al. 2007; Covington et al. 2010). Thus, a simple but attractive model is that STIM1 oligomers diffuse passively to junctions where they are trapped by interaction with the PM or Orai (Fig. 1C and see below). However, STIM1 may also be transported within cells by an active microtubule-dependent mechanism. When growing microtubules cross the 


\section{R.S. Lewis}

ER, the microtubule tip-binding protein EB1 binds to STIM1 and pulls out a new ER tubule through a "tip attachment complex" mechanism (Grigoriev et al. 2008; Honnappa et al. 2009). Although this interaction is weakened by store depletion and does not appear necessary for puncta formation (Grigoriev et al. 2008), one could imagine that STIM1-laden ER tubules are propelled in this way toward the cell periphery by microtubules, and when they encounter local sites of elevated $\mathrm{IP}_{3}$, local ER depletion releases the tubule near the PM with STIM1 primed to interact with the PM and establish or stabilize a junction. Interestingly, in two EM studies, store depletion caused the number of ER-PM junctions to increase, and overexpression of STIM1 further amplified this effect (Wu et al. 2006; Orci et al. 2009). Microtubules have also been observed aligned with cortical ER, perhaps as a memory trace of the ER's journey to the PM (Orci et al. 2009).

STIM1 movement to the cell periphery after store depletion may be regulated by the energy state of the cell. Mitochondrial depolarization impedes the movement of STIM1 oligomers to ER-PM junctions and correspondingly inhibits SOCE (Singaravelu et al. 2011). This effect appears to depend on mitofusin-2, a mitochondrial membrane protein that helps form short tethers between mitochondria and ER. One idea is that this intereference with SOCE may provide protection from $\mathrm{Ca}^{2+}$ overload in damaged cells with de-energized mitochondria (Singaravelu et al. 2011).

The formation of STIM1 puncta itself is a highly nonlinear function of $\left[\mathrm{Ca}^{2+}\right]_{\mathrm{ER}}\left(\mathrm{K}_{1 / 2}\right.$ $\sim 200 \mu \mathrm{M}$, Hill coefficient of 4-8), consistent with the idea that multiple STIM1s, each bearing a single $\mathrm{Ca}^{2+}$-binding $\mathrm{EF}$ hand, must oligomerize to be able to accumulate at ER-PM junctions (Brandman et al. 2007; Luik et al. 2008). To form puncta in the nominal absence of Orai, STIM1 requires an intact carboxyterminal polybasic domain, which has been proposed to form an amphipathic $\alpha$-helix that interacts with phosphoinositides in the plasma membrane, in effect creating a diffusion trap (Huang et al. 2006; Liou et al. 2007; Park et al.
2009). In line with this hypothesis, conditions that deplete phosphatidylinositol 4,5-bisphosphate $\left(\mathrm{PIP}_{2}\right)$ and phosphatidylinositol 3,4,5trisphosphate $\left(\mathrm{PIP}_{3}\right)$ together strongly inhibit STIM1 puncta formation, and STIM1/2 polybasic domains bind to liposomes containing these lipids in vitro (Ercan et al. 2009; Walsh et al. 2010a). Depletion of $\mathrm{PIP}_{2}$ alone by recruitment of an active 5-phosphatase to the PM only partially inhibits STIM1 puncta formation (Korzeniowski et al. 2009; Walsh et al. 2010a). However, the phosphatidylinositol 3-kinase and phosphatidylinositol 4-kinase inhibitor LY294002 largely eliminates SOCE without affecting STIM1 puncta, revealing effects of phosphatidylinositol 4-phosphate (PI 4-P) more directly on Orail (Korzeniowski et al. 2009). Together, these studies reveal potentially complex functions of lipids in SOCE, which may involve effects of $\mathrm{PIP}_{2}$ and $\mathrm{PIP}_{3}$ on STIM1 localization and of PI 4-P on Orail opening, and further work will be needed to sort out these various roles.

Deletion of the C-terminal polybasic domain reveals a second mechanism for STIM1 accumulation at junctions, mediated by binding to Orail through the CAD domain. While STIM1 lacking the polybasic domain forms puncta if coexpressed with Orail (Park et al. 2009), $I_{\text {CRAC }}$ activation is delayed under these conditions ( $\mathrm{Li}$ et al. 2007). These results suggest that the polybasic domain-PM interaction may act to accelerate $\mathrm{I}_{\mathrm{CRAC}}$ activation by creating clusters of STIM1 that more efficiently trap CRAC channels as they diffuse through ER-PM junctions.

\section{Accumulation and Activation of CRAC Channels at ER-PM Junctions}

Orail is highly mobile in the plasma membrane with a diffusion coefficient of $\sim 0.1 \mu \mathrm{m}^{2} / \mathrm{s}$ (Park et al. 2009; Madl et al. 2010), and most evidence supports a diffusion-trap mechanism in which Orail randomly encounters STIM1 at the ER-PM junctions and is trapped there by binding directly to STIM1 (Fig. 1C and see below). A recent study suggests that binding of only 1-2 STIM1s is sufficient for trapping a 
CRAC channel (Hoover and Lewis 2011). Lateral movement of Orail into the junctions is consistent with a visible loss of Orail in the spaces between STIM1 puncta after store depletion. However, store depletion may also contribute to SOCE by regulating Orail levels in the PM. In resting oocytes Orail appears to recycle constantly between the PM and an endosomal compartment, with $\sim 80 \%$ of the total Orail pool residing in the PM (Yu et al. 2010). Interestingly, the endosomal pool of Orail disappears on store depletion, prompting the suggestion that Orail binding to STIM1 at ER-PM junctions prevents its reuptake into endosomes. In platelets there is evidence for Orail insertion into the PM, but in this case in response to elevated $\left[\mathrm{Ca}^{2+}\right]_{\mathrm{i}}$ following activation of SOCE (Woodard et al. 2008). A powerful example of how regulation of Orail trafficking can modulate SOCE occurs during meiosis, when internalization of Orail helps inactivate SOCE (Yu et al. 2009).

Several groups have identified a minimal domain of STIM1 that binds to and powerfully activates CRAC channels, called CAD [CRAC Activation Domain; aa 342-448 (Park et al. 2009)], SOAR [STIM1-Orai Activating Region; aa 344-442 (Yuan et al. 2009)], or Ccb9 [aa 339-444 (Fig. 2) (Kawasaki et al. 2009)]. Park et al. showed that the binding is direct, based on GST pulldowns and copurification of Orail and CAD. Constitutive activation of $\mathrm{I}_{\mathrm{CRAC}}$ by CAD binding to Orail offers the strongest evidence to date in favor of a conformational coupling mechanism involving direct proteinprotein interactions, and argues against a diffusible messenger model (though it does not rule out the possibility that a diffusible messenger could modulate CRAC or provide a parallel activation pathway).

CAD and longer fragments of the STIM1 cytosolic domain appear to interact more strongly with the carboxyl terminus of Orail than to the amino terminus in vitro (Park et al. 2009; Zhou et al. 2010a). Although the carboxyl terminus is necessary and sufficient for Orail to colocalize with STIM1 in puncta, the amino terminus is neither necessary nor sufficient (Li et al. 2007; Muik et al. 2008).
The carboxyl terminus is weakly predicted to form a coiled-coil, and interactions with STIM1 and colocalization of Orail with STIM1 are inhibited by mutations predicted to destabilize the coiled-coil, such as L273S/D and L276D (Fig. 3) (Navarro-Borelly et al. 2008; Muik et al. 2008; Frischauf et al. 2009). The structural basis of the STIM-Orai carboxyl terminal interaction is not known, but may involve the formation of heteromeric STIM-Orai coiled-coils (Frischauf et al. 2009) or more restricted electrostatic interactions between acidic residues in the Orail carboxyl terminus (aa 272-291) and a basic region in the CC2 domain within CAD (K384-386) (Calloway et al. 2009, 2010; Korzeniowski et al. 2010).

Binding of STIM1 to the Orail amino terminus, though weaker than to the carboxyl terminus, does appear to be critical for channel activation. Because channels with a deletion of residues 1-73 from Orail still open (though at a reduced level), most attention has been focused on the highly conserved aa 73-91 (the approximate beginning of TM1) (Li et al. 2007). Deletion of aa 73-84 prevents CAD binding to the amino terminus and channel opening (Park et al. 2009). Mutations such as K85E (Lis et al. 2010) and R91W, the mutation found originally in T cells from SCID patients (Feske et al. 2006), completely prevent channel opening, apparently without preventing STIM1-Orail binding (Navarro-Borelly et al. 2008; Derler et al. 2009a), although R91W may interact with STIM1 somewhat less strongly than wild-type Orail (Fig. 3) (Muik et al. 2011). Interestingly, $\mathrm{K} 85 \mathrm{E}$ does not prevent CAD binding to the amino terminus, suggesting that this residue is required for allosteric changes leading to gate opening. R91 may serve a similar function (Derler et al. 2009a). Interestingly, this membraneproximal amino-terminal region overlaps with a calmodulin (CaM) binding site (aa 68-91), and several residues in this region (A73, Y80, W76) appear to be essential for CaM binding and $\mathrm{Ca}^{2+}$-dependent inactivation (Fig. 3) (Mullins et al. 2009). Thus, the membraneproximal region of the amino terminus is intimately tied to both activation and inactivation of CRAC channels and may provide important 
R.S. Lewis

clues about the coupling of STIM1 binding to channel gating.

Questions of Stoichiometry: STIM1, Orai1, and the CRAC Channel Complex

A number of persistent questions apply to the native stoichiometries of STIM1 and Orail that are central to understanding the functional interactions of these proteins. In resting cells inactive STIM1 is often referred to as a dimer, based on coimmunoprecipitation of orthogonally labeled STIM1s and the high resting FRET between STIM1s labeled with CFP and YFP (Baba et al. 2006; Covington et al. 2010). However, the possibility that protein overexpression in these studies may have favored formation of dimers from endogenous monomers through mass action cannot be excluded. It is important to note that even if resting dimers are an artifact of overexpression, they do not seem to perturb either the inactivity of STIM1 in resting cells or the activation of SOCE following depletion. Unfortunately, measuring the resting STIM1 stoichiometry in vivo is not a simple task. Dimeric interactions may be too labile to survive solubilization, and measuring single-molecule photobleaching of GFP-tagged STIM1 is problematic because of its mobility and by the fact that fixation depletes $\mathrm{Ca}^{2+}$ stores, possibly promoting higher-order oligomerization (E. Covington and R. Lewis, unpubl.).

More importantly, the stoichiometry of "active" STIM1 following store depletion is unknown. The CAD fragment forms a tetramer in solution (Park et al. 2009), whereas the longer STIM1 cytosolic fragments generally appear as dimers (Ji et al. 2008; Penna et al. 2008; Muik et al. 2009; Yuan et al. 2009; Zhou et al. 2010a) that may need to unfold to expose the CAD and activate Orail (Korzeniowski et al. 2010; Muik et al. 2011). These findings raise the intriguing possibility that on store depletion, STIM1 undergoes a conformational change that results in formation of a tetramer through interactions among multiple CADs (Covington et al. 2010), an idea that remains to be tested.
The subunit stoichiometry of the CRAC channel has also been the subject of debate. A tetramer of Orail subunits was first proposed by Mignen et al. based mainly on the ability of a dominant-negative pore mutant (E106Q) to inhibit currents produced by dimeric or trimeric but not tetrameric Orail concatemers (Mignen et al. 2008). In cells transfected with monomeric Orai1-GFP and subsequently fixed, quantitation of photobleaching steps of single Orail-GFP particles also supported a tetrameric stoichiometry (Ji et al. 2008), consistent with population brightness analysis of mobile Orail-GFP after photobleaching in unfixed cells (Madl et al. 2010). On the other hand, biochemical analysis and single-molecule photobleaching of Drosophila Orai-GFP (dOraiGFP) in the presence or absence of dSTIM cytosolic fragments suggested instead that Orai in resting cells is dimeric, and that STIM binding brings Orai dimers together to form the tetrameric functional channel (Penna et al. 2008). These studies raise fundamental questions about how the subunit stoichiometry of the CRAC channel is regulated, the role of STIM1 in this process, and whether changes in stoichiometry are reversible. New approaches, including structural studies will likely be necessary to resolve these questions.

Finally, recent studies have begun to show how the STIM1:Orail binding stoichiometry determines the extent of CRAC channel activation. Li et al. (2011) knocked variable numbers of STIM1 binding sites out of tetrameric Orail concatemers, revealing a graded relationship between the number of STIM1s bound and activity. Occupation of four sites was needed to evoke maximal activity, with each site thought to bind two STIM1s, leading to the conclusion that eight STIM1s must bind to fully activate the channel. Hoover and Lewis (2011) came to similar conclusions using native STIM1 and Orail coupled to mCherry and GFP. In cells with the same STIM1 expression, current magnitude increased with increasing amounts of Orai1, but dropped abruptly to near zero when the STIM1:Orail ratio in puncta fell below $\sim 2$ (or $8 /$ channel). Both studies may explain the enigma that overexpression of Orail alone often 
suppresses endogenous $\mathrm{I}_{\mathrm{CRAC}}$ (Mercer et al. 2006; Peinelt et al. 2006; Soboloff et al. 2006; Li et al. 2007); by depleting a limited supply of STIM1, excess Orail may reduce the STIM1:Orail binding stoichiometry to a level that cannot open the channel. The two studies differ in the nonlinearity of CRAC channel activation, which appeared to be a much steeper function of the STIM1:Orail ratio with monomeric Orail than with tetrameric concatemers, raising the question of whether activation of SOCE at the single-channel level is "all-ornone" or graded with the number of STIM1s bound. A previous study using noise analysis concluded that store depletion, $\mathrm{Ca}^{2+}$-dependent potentiation, and low doses of 2-APB through the stepwise recruitment of silent channels to a highly active state $(\mathrm{Po}=0.8)$ rather than a smooth increase in open probability of all the channels (Prakriya and Lewis 2006). Thus, even if channel activation is a graded function of occupancy by STIM1, when a diffusing CRAC channel encounters a cluster of STIM1 at the ER-PM junction, it may quickly become fully occupied and activate in an "allor-none" manner.

\section{Are STIM and Orai the Only Players in SOCE?}

Overexpression of STIM1 and Orail in HEK cells generates massive CRAC-like currents after store depletion, up to 100 times the size of endogenous currents (Mercer et al. 2006; Peinelt et al. 2006; Zhang et al. 2006). These findings initially suggested that these two proteins may be sufficient on their own to account for SOCE. The ability of cytosolic STIM1 fragments to activate CRAC channels outside of ER-PM junctions and independently of store depletion lends further support to this view. Zhou et al. tested the idea more rigorously using a mutant yeast system in which Orail was expressed and trapped in secretory vesicles (Zhou et al. 2010a). Because yeast does not express any homologs of Orai or STIM, it was considered unlikely they would express any possible cofactors of SOCE. Purified cytosolic fragments of STIM1 were able to bind to the vesicles and elicit $\mathrm{Ca}^{2+}$ flux, strongly suggesting that the two proteins can in fact function autonomously.

Although these findings support the idea that interactions of STIM1 and Orail alone are sufficient to elicit SOCE, they do not rule out important modulatory roles for additional proteins in vivo. An apt analogy can be made to the mechanism of exocytosis, in which purified SNARE proteins are capable of reconstituting membrane fusion to some degree by themselves in vitro but auxiliary proteins are needed to attain the high efficiency, speed, and control of secretion observed in living cells (Südhof and Rothman 2009). Orail in resting cells was first proposed to associate with another protein based on its exclusion from ER-PM junctions engineered by chemical crossbridging to have a reduced gap of $\sim 9 \mathrm{~nm}$ (Várnai et al. 2007). One candidate for such a partner could be CRACR2A, a widely expressed cytosolic protein that copurifies with Orail in HeLa cells (Srikanth et al. 2010). CRACR2A binds to both Orail and STIM1 to form a ternary complex, and contains two EF hands that trigger its dissociation at elevated $\mathrm{Ca}^{2+}$. Knockdown of CRACR2A in Jurkat cells reduced SOCE by about half, consistent with a role of enhancing the coupling between STIM1 and Orai1. Interestingly, CRACR2A's binding site on the Orail amino terminus overlaps with that of $\mathrm{Ca}^{2+}-\mathrm{CaM}$, whose binding is linked to $\mathrm{Ca}^{2+}$-dependent inactivation (CDI) of $\mathrm{I}_{\mathrm{CRAC}}$ (Mullins et al. 2009). Increased local $\left[\mathrm{Ca}^{2+}\right]_{\mathrm{i}}$ would be expected to cause CRACR2A to unbind, but it is not yet known whether this is necessary to allow $\mathrm{Ca}^{2+}-\mathrm{CaM}$ to bind and trigger CDI.

STIM1 may also associate with proteins other than Orai. Although a truncated STIM1 containing only the luminal and transmembrane domains diffuses at the expected rate for a single transmembrane ER protein, addition of the cytosolic CC1 domain slows it by about twofold (Covington et al. 2010), and oligomerization in response to store depletion slows it by another factor of two (Liou et al. 2007; Covington et al. 2010). These changes in diffusion rate are too great to be easily explained by multimerization of the transmembrane 


\section{R.S. Lewis}

domains, suggesting instead that STIM1 interacts with cytoskeletal, ER, or other cytoplasmic proteins through its CC1 domain (Covington et al. 2010). Slowing could reflect the steric hindrance of a long coiled-coil structure protruding up to $\sim 15 \mathrm{~nm}$ from the ER membrane, weak binding of STIM1 along the length of microtubules (Smyth et al. 2007; Honnappa et al. 2009), or interactions with proteins like CRACR2A (Srikanth et al. 2010) or protein complexes associated with mitochondria-ER tethers (Singaravelu et al. 2011). Golli, a widely expressed, alternatively spliced form of myelin basic protein, is another recent candidate for a STIM1-binding protein. Knockdown and overexpression experiments suggest that it inhibits SOCE in T cells when localized to the PM via a myristoylation site (Feng et al. 2006). Golli appears to interact with the isolated carboxyl terminus of STIM1 in a $\mathrm{Ca}^{2+}$-dependent manner, but thus far evidence for interaction with full-length STIM1 in cells is somewhat weak (Walsh et al. 2010b). Given the large number of hits in the original RNAi screens for SOCE suppression, continuing efforts to pull out STIM1- and Orai-interacting proteins are likely to reveal additional mechanisms that fine-tune SOCE under physiological conditions.

Toward a Molecular Basis for CRAC Channel Properties

Ion Selectivity and Permeation

The CRAC channel is unusual among $\mathrm{Ca}^{2+}$ channels in its pore properties. It has among the highest selectivity for $\mathrm{Ca}^{2+}$ over monovalent cations, comparable to that of $\mathrm{Ca}_{\mathrm{V}}$ channels (Hoth 1995), but has a narrow pore diameter (3.9 $\AA$ ) and a conductance that is among the smallest of any ion channel, being estimated from noise analysis at $\sim 20 \mathrm{fS}$ for $\mathrm{Ca}^{2+}$ (Zweifach and Lewis 1993; Prakriya and Lewis 2006). Initial studies identified mutations in several highly conserved residues that reduced the divalent ion selectivity or the sensitivity to block by trivalent cations. E106 and E190 (and their equivalent positions in dOrai) emerged as being critical for divalent selectivity, with
D110/112/114 participating in block by trivalent cations (Fig. 3) (Prakriya et al. 2006; Vig et al. 2006; Yeromin et al. 2006). To attain a more precise picture of the pore, subsequent studies applied scanning cysteine mutagenesis and probed for disulfide crosslinking (Zhou et al. 2010b) or accessibility to thiol-reactive reagents (McNally et al. 2009) as indicators of pore-lining positions. The shared conclusion was that TM1 residues line the ion-conductive pore, but those in TM3 do not, indicating that the effects of E190 mutations on ion selectivity were most likely the results of allosteric changes in protein structure (Fig. 3). The ability of $\mathrm{Cd}^{2+}$ to block the cysteine-substituted pore are consistent with a narrow pore diameter along its length (McNally et al. 2009). The emerging model of the CRAC channel pore is that of a rather flexible vestibule at the extracellular surface, a selectivity filter formed by a quartet of glutamates near the extracellular end of the pore, followed by a long narrow channel that may explain the low overall conductance. By comparing cysteine accessibility in closed vs. open channels, these methods should also be applicable to identifying the location of channel gates.

\section{$\mathrm{Ca}^{2+}$-dependent Inactivation (CDI)}

Like many $\mathrm{Ca}^{2+}$-permeable channels, CRAC channels are regulated by negative feedback from the $\mathrm{Ca}^{2+}$ that enters the cell. Rapid $\mathrm{Ca}^{2+}$ dependent inactivation (CDI) occurs over tens of $\mathrm{ms}$ and is thought to result from binding of $\mathrm{Ca}^{2+}$ to sites several $\mathrm{nm}$ from the mouth of the channel (Hoth and Penner 1992, 1993; Zweifach and Lewis 1995). A role for STIM1 in this process was first suggested by the observation that CAD peptide activates Orail without allowing CDI (Park et al. 2009). Studies of truncated STIM1 subsequently led to the identification of a region carboxy-terminal to CAD that fully restored CDI (Derler et al. 2009b; Lee et al. 2009; Mullins et al. 2009). The inactivation domain (ID STIM $_{\text {; }}$ aa 470-491) contains a stretch of seven acidic residues that exert a powerful influence over the extent of CDI (Fig. 2). Neutralization of pairs of residues either reduced or enhanced CDI (Mullins et al. 2009), 
whereas neutralization of 5-7 residues completely eliminated CDI (Derler et al. 2009b; Lee et al. 2009; Mullins et al. 2009). Preliminary evidence from ${ }^{45} \mathrm{Ca}$ overlays suggested that this domain may bind $\mathrm{Ca}^{2+}$ weakly, but the effects of neutralizing mutations on $\mathrm{Ca}^{2+}$ binding were not in every case consistent with their effects on CDI (Mullins et al. 2009). Thus, its potential role as a $\mathrm{Ca}^{2+}$ binding site for $\mathrm{CDI}$ is at present undetermined.

Evidence is stronger for $\mathrm{CaM}$ as the $\mathrm{Ca}^{2+}$ sensor for CDI. Early work by Rychkov et al. showed evidence for a role of $\mathrm{CaM}$, based on partial suppression of CDI by overexpressing a mutant $\mathrm{Ca}^{2+}$-nonbinding CaM or a CaM inhibitory peptide (Litjens et al. 2004). Subsequent work revealed that $\mathrm{CaM}$ binds in a $\mathrm{Ca}^{2+}$ dependent manner to the Orail amino terminus in a region adjacent to the start of TM1 (aa 68-90; Fig. 3) (Mullins et al. 2009). Mutations that prevent CaM binding (A73E, W76E/ $\mathrm{A} / \mathrm{S}$, and $\mathrm{Y} 80 \mathrm{E})$ completely eliminate $\mathrm{CDI}$, whereas mutations that preserve binding (Y80A/ S) display CDI with accelerated kinetics. Much remains to be understood about how CaM operates to control CDI, such as the location of the apo-CaM binding site, and the role of the CaM binding domain in controlling CDI kinetics.

In addition to the amino terminus, other regions of Orail also participate in CDI. Alanine substitutions in the intracellular II-III loop at aa 151-154 eliminate CDI, whereas application of a soluble wild-type peptide containing this region reduces current unless it bears the alanine mutations (Fig. 3) (Srikanth et al. 2010). Srikanth et al. suggest that the II-III loop of Orail may function as a blocking particle in CDI to inhibit conduction. Another study has shown that mutations that increase Orail pore size (E106D, E190Q) greatly reduce or eliminate CDI (Yamashita et al. 2007). These findings raise the possibility that the inactivation gate may involve elements of the selectivity filter, as has been proposed for $\mathrm{Ca}_{\mathrm{V}}$ and $\mathrm{K}_{\mathrm{V}}$ channels.

One complication in designing and interpreting CDI experiments is that the STIM1:Orail binding stoichiometry has a powerful effect on the extent of CDI. Scrimgeour et al. (2009) initially reported that CDI was normal in cells expressing a high ratio of STIM1:Orail but was lost in cells with low expression ratios. In an extension of this work, we found that CDI fell in parallel with channel activation as the STIM1:Orail ratio fell below $\sim 2$, suggesting that full inactivation requires binding of eight STIM1s to the channel (Hoover and Lewis 2011). Thus, the number of STIM1s bound to a CRAC channel determines not only its ability to open, but its propensity to inactivate in response to $\mathrm{Ca}^{2+}$ entry.

One important concept that has emerged from the work on CDI described above is that the CRAC channel itself is not merely a multimer of Orail, but is more accurately considered as a multiprotein complex. It binds $\mathrm{CaM}$, which acts as a subunit to promote CDI. In addition, the requirement for STIM1 in enabling the channel to gate in response to an extracellular ligand $\left(\mathrm{Ca}^{2+}\right)$ implies that STIM1 also acts as a channel subunit and not merely as an activating ligand.

\section{FUNCTIONAL ROLES OF STIM AND ORAI: INSIGHTS FROM GENETICS}

Determining the precise functions of STIM and Orai in intact organisms has long been frustrated by a lack of highly specific pharmacological inhibitors. However, new insights and unexpected roles have been revealed by the phenotypes of genetically engineered STIM $1 / 2$ and Orail mutant mice as well as human patients with naturally occurring loss-of-function mutations in STIM1 or Orail. Thus far, these studies have established important functions for STIM and Orai in the immune system, skeletal muscle, and platelets, among other cells and tissues.

Three distinct mutations causing loss of Orail function have been described in unrelated human families, as well as one frameshift mutation in STIM1 leading to a loss of protein expression; in mice, Orai1-, STIM1-, and STIM2-deficient mice have been engineered by homologous recombination or insertional mutagenesis (for reviews see Feske 2010). It is noteworthy that the clinical pathophysiologies caused by a loss of STIM1 or Orail function 
mostly overlap, suggesting that STIM1's critical functions in humans are performed primarily through Orail rather than other targets (Feske 2010). There are differences in phenotypes between humans and mice that may be caused by environment (the real world vs. animal care facilities or pathogen-free conditions), genetic background (e.g., highly inbred mouse strains), or the expression patterns of different Orai isoforms. Here I will attempt to identify the generalities that apply to both humans and mice and describe some of the unexpected results; a fuller discussion of these genetic studies is available in several excellent reviews (Baba and Kurosaki 2009; Feske 2009, 2010; Vig and Kinet 2009; Hogan et al. 2010).

\section{Immune Cells}

Loss of STIM1 or Orail function in humans causes severe combined immunodeficiency (SCID), a lethal condition marked by recurrent opportunistic infections, the only therapy being a functional hematopoietic stem cell transplant. Although normal numbers of T cells are present in these patients, they appear largely nonfunctional because of an inability of antigen receptor engagement to generate $\mathrm{Ca}^{2+}$ signals that regulate gene expression during $\mathrm{T}$ cell activation (Feske et al. 2001). These findings have triggered intense interest in developing specific pharmacologic inhibitors of the CRAC channel to treat a variety of autoimmune disorders. In mice, the absence of Orail or STIM1 function causes multiple defects of cytokine expression in T cells (interleukin (IL)- 2, interferon- $\gamma$, IL-4, IL-10) (Gwack et al. 2008; Oh-Hora et al. 2008), and in mast cells, defective synthesis or release of inflammatory mediators (tumor necrosis factor- $\alpha$, IL-6, serotonin, and leukotriene $\mathrm{C}_{4}$ ) leads to a reduced anaphylaxis response in vivo (Baba et al. 2008; Vig et al. 2008). B-cell targeted deletion of STIM1 and STIM2 revealed a novel role for SOCE in enabling B cells to limit autoimmunity; in these animals reduced secretion of the anti-inflammatory cytokine IL-10 was linked to increased severity of experimental autoimmune encephalomyelitis, a model for multiple sclerosis (Matsumoto et al. 2011).
Interestingly, loss of STIM or Orail function does not eliminate all immune activity. $\mathrm{T}$ cell-dependent antibody responses and graft vs. host disease response appear relatively unaffected in STIM1 ${ }^{-/-}$mice (Beyersdorf et al. 2009). Partial function of B cells is also evident in STIM1- or Orail-deficient patients who develop lymphoproliferative disease and an autoimmune attack on their own neutrophils and thrombocytes (McCarl et al. 2009; Picard et al. 2009). A related autoimmune phenotype was observed in STIM1/STIM2 deficient mice (Oh-Hora et al. 2008; Oh-hora 2009). The autoimmunity is likely caused by defective generation of regulatory $\mathrm{T}\left(\mathrm{T}_{\text {reg }}\right)$ cells that normally act to suppress $\mathrm{T}$ and $\mathrm{B}$ cell function. Finally, while there is much evidence supporting a role of sustained TCR-mediated $\mathrm{Ca}^{2+}$ signals in positive and negative selection of T cells during development in the thymus, development appears to proceed normally in the absence of STIM1 or Orail; the same is true for development of mast cells and platelets. These findings raise a number of intriguing questions. Can other $\mathrm{Ca}^{2+}$ channels substitute for STIM1 and Orai1 (e.g., Orai2 or 3, $\mathrm{Ca}_{\mathrm{V}}$, or TRPC channels, $\mathrm{P} 2 \mathrm{X}$ receptors, or something else?), or are the $\mathrm{Ca}^{2+}$ requirements for some cell functions low enough that $\mathrm{ER} \mathrm{Ca}^{2+}$ release alone is sufficient? Finally, what makes the development of $\mathrm{T}_{\text {reg }}$ cells relatively sensitive to the loss of STIM or Orai1, while that of the other $\mathrm{T}$ cell subsets is not affected?

\section{Platelets}

$\mathrm{Ca}^{2+}$ is an essential signal for platelet activation events leading to clotting, hemostasis and thrombosis. Platelets express several parallel $\mathrm{Ca}^{2+}$ entry pathways, which made it difficult to define the role of SOCE in specific platelet functions until the generation of genetically engineered mice. In mice that are STIM1- or Orail-deficient or homozygous for the nonfunctional Orail R93W gene, platelets show deficient $\mathrm{Ca}^{2+}$ responses to collagen and thrombin with defects in activation and thrombus formation in vitro (Varga-Szabo et al. 2008; Bergmeier et al. 2009; Braun et al. 2009). 
Interestingly, these mice are protected in experimental models of arterial thrombosis and ischemic brain infarction, while displaying only a mild prolongation of bleeding time. Thus, STIM1 and Orail may not be absolutely essential for most of the rapid responses of platelets to activating factors (e.g., shape change, integrin activation, and secretion), but are perhaps more important for late responses such as stabilization of the thrombus, clot retraction, coagulant activity, and recruitment of cells to sites of injury (Varga-Szabo et al. 2009). These findings suggest the potential therapeutic use of CRAC channel blockers to treat ischemic cardiovascular or cerebrovascular disease.

\section{Sweat Glands and Teeth}

STIM1 and Orail appear to be required for the normal development and function of some ectodermally-derived tissues, such as sweat glands and teeth. In humans lacking Orail function, eccrine sweat glands do not function properly (whether this is a developmental or a purely functional defect is unclear), and this leads to dry skin and defects in thermoregulation manifest as recurrent fever (McCarl et al. 2009). The dental enamel in patients lacking STIM1 or Orail expression also fails to develop properly, implicating SOCE in the transepithelial transport of $\mathrm{Ca}^{2+}$ during formation of enamel (Picard et al. 2009; McCarl et al. 2009). STIM1- and Orail-knockout mice may provide a useful experimental model for this poorly understood process.

\section{Skeletal Muscle}

More unexpected roles of STIM1 and Orail have emerged from genetic studies of skeletal muscle. The first hints for a function came from observations that CRAC-deficient SCID patients display a mild muscle myopathy with reduced strength and endurance (Partiseti et al. 1994; McCarl et al. 2009). STIM1 and Orail were later shown to be highly expressed in both human and mouse skeletal muscle (Williams et al. 2001; Gwack et al. 2008; Stiber et al. 2008; Vig et al. 2008; McCarl et al.
2009), and STIM1-deficient mice exhibit reduced muscle mass and susceptibility to fatigue (Stiber et al. 2008). The reduced mass is presumably caused by a defect in muscle development, as knockdown of STIM1, STIM2, or Orail or 3 inhibits the differentiation of myoblasts into myotubes and underlying gene activation events (Darbellay et al. 2008, 2010). Early fatigue is consistent with a role for STIM1 and Orail in maintaining SR $\mathrm{Ca}^{2+}$ content during periods of high frequency muscle activity, when slow depletion of $\mathrm{Ca}^{2+}$ from the SR would normally activate SOCE to replenish the SR $\mathrm{Ca}^{2+}$ deficit and thus maintain $\mathrm{Ca}^{2+}$ release transients and the force of contraction (Pan et al. 2002; Stiber et al. 2008). An intriguing feature of SOCE in muscle is that it is orders of magnitude faster than in nonexcitable cells (Launikonis and Ríos 2007), commencing in some cases within milliseconds of $\mathrm{Ca}^{2+}$ release from the SR (Edwards et al. 2010). Several models have been proposed to explain how prelocalization of STIM1 and Orail at the triadic junction may confer these extraordinarily rapid activation kinetics (Dirksen 2009; Launikonis et al. 2010).

\section{FUTURE DIRECTIONS}

\section{Formation and Function of the ER-PM Junctions}

Because SOCE depends absolutely on the direct contact of STIM and Orai at ER-PM junctions, the number, size, and intermembrane dimensions of these structures will exert profound effects on SOCE. However, little is known about how ER-PM junctions form and disassemble. Depletion of stores and STIM1 overexpression increases the number and extent of ER-PM junctions (Wu et al. 2006; Orci et al. 2009), suggesting a role for STIM1 in their formation or stabilization. Similarly, overexpression or knockdown of the widely expressed SR/ER protein junctate increases or decreases the abundance of junctions, respectively, although this was store-independent (Treves et al. 2004, 2010). Overexpression of TRPC3 also increased junction formation, suggesting that multiple 
proteins may participate in bridging the two membranes. Periodic electron densities have been reported between the ER and PM at junctate-induced junctions, but thus far their molecular basis is unknown, and the relationship to junctions in which STIM and Orai accumulate is unclear (Treves et al. 2010).

The highly restricted region of $\mathrm{Ca}^{2+}$ entry at ER-PM junctions offers attractive opportunities for local signaling within $\mathrm{Ca}^{2+}$ microdomains to effector proteins (Luik et al. 2006). SOCE has been shown to activate or repress particular enzymes with high specificity, including adenylate cyclases (Willoughby and Cooper 2007), the plasma membrane $\mathrm{Ca}^{2+}$ pump (Bautista and Lewis 2004), and phospholipase $\mathrm{A}_{2}$ (Chang et al. 2008). The evidence for local signaling is mostly based on two approaches. One is to show that BAPTA, a fast $\mathrm{Ca}^{2+}$ chelator, can interrupt the activation of the target by SOCE, whereas the slower buffer EGTA cannot, suggesting that the target is located somewhere between the calculated capture distances of the two chelators (tens of nanometers from the channels). The other approach is to show that when SOCE and non-SOCE pathways are engaged to produce the same global $\left[\mathrm{Ca}^{2+}\right]_{\mathrm{i}}$ increase, only SOCE activates the target. Using these approaches, recent studies suggest that transcriptional pathways may be activated preferentially near CRAC channels (di Capite et al. 2009; $\mathrm{Ng}$ et al. 2009). $\mathrm{Ca}^{2+}$ entry through CRAC channels has long been known to drive gene expression through NFAT and other factors, and the efficiency and specificity of gene activation depends on the amplitude and duration of sustained $\mathrm{Ca}^{2+}$ signals and the frequency of $\mathrm{Ca}^{2+}$ oscillations triggered through CRAC channels (Dolmetsch et al. 1997, 1998). Recently, Parekh and colleagues presented evidence that NFAT activation, assayed by nuclear accumulation, is triggered preferentially in the close vicinity of CRAC channels rather than in the cytosol (Kar et al. 2011). This finding is remarkable, given that the NFAT-activating phosphatase calcineurin $(\mathrm{CN})$ is present in the cytoplasm and its $\mathrm{Ca}^{2+}$ sensitivity is sufficiently high to dephosphorylate NFAT at submicromolar levels of global cytosolic $\mathrm{Ca}^{2+}$
(Stemmer and Klee 1994). One possible explanation is that cytoplasmic $\mathrm{CN}$ activity is weak enough to be subverted by cytoplasmic NFAT kinases, whereas junctional $\mathrm{CN}$ activity more completely dephosphorylates NFAT, enabling it to run the cytoplasmic kinase gauntlet and reach the nucleus. Further studies may shed light on the details of this mechanism.

\section{Regulation of SOCE in a Physiological Context}

One expansive goal for further research is to determine the many levels at which SOCE can be regulated under physiological conditions. The great majority of studies to date have been conducted using TG, high intracellular $\mathrm{IP}_{3}$, ionomycin, or chelators, all of which deplete the ER completely throughout the cell. Physiological responses are likely to be much more localized, particularly when stimuli are spatially restricted. A particularly interesting example occurs during immune synapse formation between $\mathrm{T}$ cells and antigen-presenting cells (APCs), in which the $\mathrm{T}$ cell receptors engage peptide-MHC complexes on the APC. Shortly after cell-cell contact, STIM1 and Orail change their localization, accumulating initially at the synapse and then appearing to move in tandem to the distal end of the cell (Barr et al. 2008; Lioudyno et al. 2008). $\mathrm{Ca}^{2+}$ imaging shows a domain of elevated $\left[\mathrm{Ca}^{2+}\right]_{i}$ at the synapse, where it could potentially affect synapse stability, cytoskeletal remodeling, secretion, and other $\mathrm{Ca}^{2+}$-dependent events (Lioudyno et al. 2008). These studies raise many interesting questions about the mechanisms involved in polarizing the SOCE machinery and the potentially different consequences of localizing STIM1-Orail complexes to the two poles of the cell.

STIM1 is known to be phosphorylated in situ (Manji et al. 2000), but functional effects are only beginning to be explored. Among multiple sites of phosphorylation, several (S575, S608, S621) are phosphorylated by ERK1/2 and this increases after store depletion (PozoGuisado et al. 2010). Alanine mutations at these sites significantly repressed SOCE, suggesting that phosphorylation may serve as a powerful 
positive modulator. Conversely, Smyth et al. linked phosphorylation in the cytoplasmic region to the suppression of SOCE during mitosis (Smyth et al. 2009). Among multiple sites, phosphorylation at S486 and S668 were found to be most potent in preventing STIM1 puncta formation and suppressing SOCE (Fig. 2). The physiological role of SOCE suppression is not yet clear, although a slight slowing of cell proliferation was seen in cells overexpressing a truncated STIM1 that functions during mitosis. It will be interesting to see if phosphorylation affects cell function independently of suppressing $\mathrm{Ca}^{2+}$ entry. From these early studies it is already clear that phosphorylation has the potential to modulate CRAC channel activity in response to multiple environmental cues.

Oxidation may also affect STIM1 and Orai1 function independently of ER $\mathrm{Ca}^{2+}$, possibly modulating SOCE under conditions of cellular stress or inflammation. Oxidation by $\mathrm{H}_{2} \mathrm{O}_{2}$ or buthionine sulfoximine can cause STIM1 to form puncta and open Orail channels (Hawkins et al. 2010). One proposed mechanism involves S-glutathionylation of $\mathrm{C} 56$, which then reduces $\mathrm{Ca}^{2+}$ binding by the adjacent EF hand. In this way STIM1 may act as a cellular sensor for oxidant stress, although an indirect effect of oxidants on SOCE through depletion of $\mathrm{Ca}^{2+}$ stores has not been excluded. On the other hand, oxidation also inhibits SOCE by reducing Orail activity (Bogeski et al. 2010). This effect has been traced primarily to C195, and occurs with Orail but not Orai3. Interestingly, SOCE in effector T cells is more resistant to inhibition by ROS than in naïve T cells, which may result from increased expression of Orai3 relative to Orail in effector cells. Bogeski et al. propose that the increased Orai3:Orail ratio is an adaptation that allows effector T cells to proliferate and optimize cytokine production in the oxidizing environment of injured or inflamed tissue. Understanding how the stimulatory and inhibitory effects of oxidation are integrated during responses to physiological stimuli is an important goal.

Temperature is another factor that has been largely overlooked in studies of STIM1-Orail function; even though the majority of studies use mammalian proteins, room temperature has been the norm. Interestingly, Xiao et al. (2011) showed that STIM1 is in fact highly temperature-dependent, and it begins to form puncta without store depletion at temperatures $>35^{\circ} \mathrm{C}$. Interestingly (and fortunately for us), this does not by itself activate $\mathrm{Ca}^{2+}$ entry, but Orail channels open during subsequent cooling. It is not known whether binding to Orail is completely inhibited at the high temperature, or some more subtle change is involved. One proposal is that this thermosensitivity may prime immune cells for greater activity during fever as they circulate between the body core and the cooler periphery, or play a role in skeletal muscle physiology during intense exercise (Xiao et al. 2011). These findings also raise the possibility that at mammalian physiological temperatures the $\left[\mathrm{Ca}^{2+}\right]_{\mathrm{ER}}$ threshold for STIM1 oligomerization may be shifted to higher $\left[\mathrm{Ca}^{2+}\right]_{\mathrm{ER}}$ than has been measured at room temperature (Brandman et al. 2007; Luik et al. 2008), making STIM1 more responsive to small changes in $\left[\mathrm{Ca}^{2+}\right]_{\mathrm{ER}}$ than currently thought.

\section{Multiple Roles for STIM1 in $\mathrm{Ca}^{2+}$ Channel Regulation}

\section{TRPC Channels}

Mammalian TRPC channels are weakly $\mathrm{Ca}^{2+}$ permeable channels with a long history of association with SOCE, but whether they are truly store-dependent is still being debated (DeHaven et al. 2009; Wang et al. 2010). The strongest evidence of store-dependent activation comes from charge-swapping experiments suggesting that a di-lysine motif in STIM1 interacts with a conserved di-aspartate domain in TRPC1 and other TRPCs to activate these channels following store depletion (Zeng et al. 2008). One complication in assessing whether TRPCs are store-operated has been that PLC-coupled agonists have been used in most cases to activate the channels, stimulating second-messenger (diacylglycerol, $\mathrm{PIP}_{2}, \mathrm{IP}_{3}$ ) and store-depletion pathways in parallel. The definitive tests for store-operated function (i.e., channel activation by store depletion independent of receptor 


\section{R.S. Lewis}

activation or changes in $\left.\left[\mathrm{Ca}^{2+}\right]_{\mathrm{i}}\right)$ have in most cases not been performed, or have given ambiguous results. For example, TRPC7, once thought to be store-operated because it is activated by TG, was later found not to be activated by $\mathrm{IP}_{3}$ or ionomycin even though they also empty the ER (DeHaven et al. 2009). One step toward settling this debate would be to test whether a variety of receptor-independent store-depletion stimuli (SERCA blockers, cytosolic and $\mathrm{ER} \mathrm{Ca}^{2+}$ chelators, lipophilic $\mathrm{Ca}^{2+}$ ionophores, TPEN) all activate TRPC channels under conditions of heavy cytosolic buffering at resting $\left[\mathrm{Ca}^{2+}\right]_{\mathrm{i}}$ levels. Unfortunately, these tests also complicated by potential crosstalk between Orail channels and TRPC channels mediated through local increases in $\left[\mathrm{Ca}^{2+}\right]_{\mathrm{i}}$ entering via Orail. In fact, the relation between STIM1, Orail, and TRPCs could be quite complex, given evidence that TRPC channel activation or insertion into the PM may be affected by local changes in $\left[\mathrm{Ca}^{2+}\right]_{\mathrm{i}}$ through other channels (Gross et al. 2009; Cheng et al. 2011). A critical challenge for future studies is to understand this relation and how TRPC channels act in concert with STIM1 and Orail to shape store-dependent $\mathrm{Ca}^{2+}$ signals.

\section{ARC Channels}

Arachidonate-regulated $\mathrm{Ca}^{2+}$ (ARC) channels are similar in terms of $\mathrm{Ca}^{2+}$ selectivity and conductance to the CRAC channel, but differ in lacking $\mathrm{CDI}$ and sensitivity to $2-\mathrm{APB}$, and most importantly are activated by arachidonic acid rather than store depletion (Shuttleworth 2009). STIM1 is necessary for their activation, but only the fraction of STIM1 that is constitutively present in the PM (comprising about $10 \%-20 \%$ of the total STIM1 pool in most cells) (Mignen et al. 2007). Concatemer studies suggest that ARC channels form as a pentamer of Orai subunits $(3 \times$ Orai $1+2 \times$ Orai 3$)$, and glutamine substitutions for glutamates at E106 in Orail or the corresponding location in Orai3 (E81) both inhibit conductance, suggesting the formation of a pentameric glutamatergic selectivity filter (Mignen et al. 2009). Ion selectivity studies with less extreme aspartate substitutions and sizing the wt pentameric pore under divalent-free conditions will help validate this model and help relate its ion selectivity mechanism to that of the tetrameric CRAC channel. Tail swapping experiments have indicated that arachidonic acid selectivity requires two amino-terminal Orai3 regions in the pentamer (Thompson et al. 2010). Much remains to be learned about how STIM1 regulates the ARC channels, and how ARC and CRAC channel synthesis are controlled in cells that express both Orail and Orai3.

\section{Ca ${ }_{V}$ Channels}

STIM1 was recently and unexpectedly discovered to exert reciprocal actions on storeoperated and voltage-gated $\mathrm{Ca}^{2+}\left(\mathrm{Ca}_{\mathrm{V}} 1.2\right)$ channels (Park et al. 2010; Wang et al. 2010). STIM1 inhibits $\mathrm{Ca}_{\mathrm{V}} 1.2$ channel function in two ways. First, store-depletion acts through STIM1 to acutely inhibit voltage-gated opening of $\mathrm{Ca}_{\mathrm{V}} 1.2$; this effect ranges from a modest $15 \%$ (Park et al. 2010) to nearly total inhibition (Wang et al. 2010). In addition, STIM1 expression can nearly completely suppress Cav1.2 by stimulating its internalization (Park et al. 2010). These effects appear to be caused by binding of the CAD domain of STIM1 to the carboxyl terminus of $\mathrm{Ca}_{\mathrm{V}}$ 1.2. Many of the details of the mechanisms remain to be worked out, and further studies will be needed to understand how general these phenomena are and whether the crosstalk extends to other members of the $\mathrm{Ca}_{V}$ family. The effects of STIM1 on $\mathrm{Ca}_{\mathrm{V}} 1.2$ channel function may help explain how PLC-coupled receptors inhibit voltagegated $\mathrm{Ca}^{2+}$ signaling, and in cells that express both $\mathrm{Ca}_{\mathrm{V}} 1.2$ and Orail, the reciprocal regulation of these channels provides a new mechanism to enable the selective activation of channel-specific signaling pathways.

\section{CONCLUSION}

The identification of the STIM and Orai genes has led to a remarkable wave of progress in understanding the mechanism of SOCE, to the point where the major steps are now known 
and have been described in at least a qualitative way. There clearly remains much that is not understood at a mechanistic level, and application of increasingly sophisticated physiological, cell biological, biochemical and structural approaches will be needed to fill in these gaps. It is hoped that with a more detailed mechanistic picture of CRAC channel function and regulation, we may better understand the full diversity of their functions in vivo, and ultimately develop new strategies to control them in the treatment of human disease.

\section{ACKNOWLEDGMENTS}

Work in the Lewis laboratory is supported by the National Institutes of Health (NIH GM45374).

\section{REFERENCES}

Baba Y, Kurosaki T. 2009. Physiological function and molecular basis of STIM1-mediated calcium entry in immune cells. Immunol Rev 231: 174-188.

Baba Y, Hayashi K, Fujii Y, Mizushima A, Watarai H, Wakamori M, Numaga T, Mori Y, Iino M, Hikida M, et al. 2006. Coupling of STIM1 to store-operated $\mathrm{Ca}^{2+}$ entry through its constitutive and inducible movement in the endoplasmic reticulum. Proc Natl Acad Sci 103: 16704-16709.

Baba Y, Nishida K, Fujii Y, Hirano T, Hikida M, Kurosaki T. 2008. Essential function for the calcium sensor STIM in mast cell activation and anaphylactic responses. Nat Immunol 9: 81-88.

Barr VA, Bernot KM, Srikanth S, Gwack Y, Balagopalan L, Regan CK, Helman DJ, Sommers CL, Oh-Hora M, Rao A, et al. 2008. Dynamic movement of the calcium sensor STIM1 and the calcium channel Orail in activated T-cells: Puncta and distal caps. Mol Biol Cell 19: $2802-$ 2817.

Bautista DM, Lewis RS. 2004. Modulation of plasma membrane calcium-ATPase activity by local calcium microdomains near CRAC channels in human T cells. J Physiol 556: $805-817$.

Bergmeier W, Oh-Hora M, McCarl CA, Roden RC, Bray PF, Feske S. 2009. R93W mutation in Orail causes impaired calcium influx in platelets. Blood 113: 675-678.

Beyersdorf N, Braun A, Vögtle T, Varga-Szabo D, Galdos RR, Kissler S, Kerkau T, Nieswandt B. 2009. STIM1-independent $\mathrm{T}$ cell development and effector function in vivo. J Immunol 182: 3390-3397.

Bogeski I, Kummerow C, Al-Ansary D, Schwarz EC, Koehler R, Kozai D, Takahashi N, Peinelt C, Griesemer D, Bozem $\mathrm{M}$, et al. 2010. Differential redox regulation of ORAI ion channels: A mechanism to tune cellular calcium signaling. Sci Signal 3: ra24.
Brandman O, Liou J, Park W, Meyer T. 2007. STIM2 is a feedback regulator that stabilizes basal cytosolic and endoplasmic reticulum $\mathrm{Ca}^{2+}$ levels. Cell 131: 1327-1339.

Braun A, Varga-Szabo D, Kleinschnitz C, Pleines I, Bender M, Austinat M, Bösl M, Stoll G, Nieswandt B. 2009. Orail (CRACM1) is the platelet SOC channel and essential for pathological thrombus formation. Blood 113: 2056-2063.

Cahalan MD, Zhang SL, Yeromin AV, Ohlsen K, Roos J, Stauderman KA. 2007. Molecular basis of the CRAC channel. Cell Calcium 42: 133-144.

Calloway N, Vig M, Kinet J-P, Holowka D, Baird B. 2009. Molecular clustering of STIM1 with Orail/CRACM1 at the plasma membrane depends dynamically on depletion of $\mathrm{Ca}^{2+}$ stores and on electrostatic interactions. Mol Biol Cell 20: 389-399.

Calloway NT, Holowka DA, Baird BA. 2010. A Basic Sequence In STIM1 Promotes $\mathrm{Ca}^{2+}$ Influx By Interacting With The C-Terminal Acidic Coiled-Coil Of Orail. Biochemistry 49: 1067-1071.

Chang W-C, di Capite J, Singaravelu K, Nelson C, Halse V, Parekh AB. 2008. Local $\mathrm{Ca}^{2+}$ influx through $\mathrm{Ca}^{2+}$ release-activated $\mathrm{Ca}^{2+}$ (CRAC) channels stimulates production of an intracellular messenger and an intercellular pro-inflammatory signal. J Biol Chem 283: 4622-4631.

Cheng KT, Liu X, Ong HL, Swaim W, Ambudkar IS. 2011. Local $\mathrm{Ca}^{2+}$ entry via Orail regulates plasma membrane recruitment of TRPC1 and controls cytosolic $\mathrm{Ca}^{2+}$ signals required for specific cell functions. PLoS Biol 9: e1001025.

Covington ED, Wu MM, Lewis RS. 2010. Essential role for the CRAC activation domain in store-dependent oligomerization of STIM1. Mol Biol Cell 21: 1897-1907.

Darbellay B, Arnaudeau S, König S, Jousset H, Bader C, Demaurex N, Bernheim L. 2008. STIM1 and Orai1dependent store-operated calcium entry regulates human myoblast differentiation. J Biol Chem 284: 5370-5380.

Darbellay B, Arnaudeau S, Ceroni D, Bader CR, Konig S, Bernheim L. 2010. Human muscle economy myoblast differentiation and excitation-contraction coupling use the same molecular partners, STIM1 and STIM2. J Biol Chem 285: 22437-22447.

DeHaven WI, Jones BF, Petranka JG, Smyth JT, Tomita T, Bird GS, Putney JW. 2009. TRPC channels function independently of STIM1 and Orail. J Physiol 587: 2275-2298.

Derler I, Fahrner M, Carugo O, Muik M, Bergsmann J, Schindl R, Frischauf I, Eshaghi S, Romanin C. 2009a. Increased hydrophobicity at the $\mathrm{N}$ terminus/membrane interface impairs gating of the severe combined immunodeficiency-related ORAI1 mutant. J Biol Chem 284: 15903-15915.

Derler I, Fahrner M, Muik M, Lackner B, Schindl R, Groschner K, Romanin C. 2009b. A Ca ${ }^{2+}$ release-activated $\mathrm{Ca}^{2+}$ (CRAC) modulatory domain (CMD) within STIM1 mediates fast $\mathrm{Ca}^{2+}$-dependent inactivation of ORAI1 channels. J Biol Chem 284: 24933-24938.

di Capite J, Ng SW, Parekh AB. 2009. Decoding of cytoplasmic $\mathrm{Ca}^{2+}$ oscillations through the spatial signature drives gene expression. Curr Biol 19: 853-858.

Dirksen RT. 2009. Checking your SOCCs and feet: The molecular mechanisms of $\mathrm{Ca}^{2+}$ entry in skeletal muscle. J Physiol 587: 3139-3147. 


\section{R.S. Lewis}

Dolmetsch RE, Lewis RS. 1994. Signaling between intracellular $\mathrm{Ca}^{2+}$ stores and depletion-activated $\mathrm{Ca}^{2+}$ channels generates $\left[\mathrm{Ca}^{2+}\right]_{\mathrm{i}}$ oscillations in T lymphocytes. $J$ Gen Physiol 103: 365-388.

Dolmetsch RE, Lewis RS, Goodnow CC, Healy JI. 1997. Differential activation of transcription factors induced by $\mathrm{Ca}^{2+}$ response amplitude and duration. Nature 386: 855-858.

Dolmetsch RE, Xu K, Lewis RS. 1998. Calcium oscillations increase the efficiency and specificity of gene expression. Nature 392: 933-936.

Edwards JN, Murphy RM, Cully TR, von Wegner F, Friedrich O, Launikonis BS. 2010. Ultra-rapid activation and deactivation of store-operated $\mathrm{Ca}^{2+}$ entry in skeletal muscle. Cell Calcium 47: 458-467.

Ercan E, Momburg F, Engel U, Temmerman K, Nickel W, Seedorf M. 2009. A conserved, lipid-mediated sorting mechanism of yeast Ist 2 and mammalian STIM proteins to the peripheral ER. Traffic 10: 1802-1818.

Fahrner M, Muik M, Derler I, Schindl R, Fritsch R, Frischauf I, Romanin C. 2009. Mechanistic view on domains mediating STIM1-Orai coupling. Immunol Rev 231: 99-112.

Feng J-M, Hu YK, Xie L-H, Colwell CS, Shao XM, Sun X-P, Chen B, Tang H, Campagnoni AT. 2006. Golli protein negatively regulates store depletion-induced calcium influx in T cells. Immunity 24: 717-727.

Feske S. 2009. ORAI1 and STIM1 deficiency in human and mice: Roles of store-operated $\mathrm{Ca}^{2+}$ entry in the immune system and beyond. Immunol Rev 231: 189-209.

Feske S. 2010. CRAC channelopathies. Pflugers Arch 460: 417-435.

Feske S, Giltnane J, Dolmetsch R, Staudt LM, Rao A. 2001. Gene regulation mediated by calcium signals in T lymphocytes. Nat Immunol 2: 316-324.

Feske S, Prakriya M, Rao A, Lewis R. 2005. A severe defect in CRAC $\mathrm{Ca}^{2+}$ channel activation and altered $\mathrm{K}^{+}$channel gating in $\mathrm{T}$ cells from immunodeficient patients. $J$ Exp Med 202: 651-662.

Feske S, Gwack Y, Prakriya M, Srikanth S, Puppel S, Tanasa B, Hogan P, Lewis R, Daly M, Rao A. 2006. A mutation in Orail causes immune deficiency by abrogating CRAC channel function. Nature 441: 179-185.

Frischauf I, Muik M, Derler I, Bergsmann J, Fahrner M, Schindl R, Groschner K, Romanin C. 2009. Molecular determinants of the coupling between STIM1 and Orai channels: Differential activation of Orail-3 channels by a STIM1 coiled-coil mutant. J Biol Chem 284: 2169621706.

Grigoriev I, Gouveia SM, van der Vaart B, Demmers J, Smyth JT, Honnappa S, Splinter D, Steinmetz MO, Putney JW, Hoogenraad CC, Akhmanova A. 2008. STIM1 is a MT-plus-end-tracking protein involved in remodeling of the ER. Curr Biol 18: 177-182.

Gross S, Guzman G, Wissenbach U, Philipp S, Zhu M, Bruns D, Cavalie A. 2009. TRPC5 is a $\mathrm{Ca}^{2+}$-activated channel functionally coupled to $\mathrm{Ca}^{2+}$-selective ion channels. J Biol Chem 284: 34423-34432.

Grynkiewicz G, Poenie M, Tsien RY. 1985. A new generation of $\mathrm{Ca}^{2+}$ indicators with greatly improved fluorescence properties. J Biol Chem 260: 3440-3450.
Gwack Y, Srikanth S, Oh-Hora M, Hogan PG, Lamperti ED, Yamashita M, Gelinas C, Neems DS, Sasaki Y, Feske S, Rao A, et al. 2008. Hair loss and defective T- and B-cell function in mice lacking ORAI1. Mol Cell Biol 28: 5209-5222.

Hawkins BJ, Irrinki KM, Mallilankaraman K, Wang Y, Bhanumathy CD, Subbiah R, Ritchie MF, Soboloff J, Baba Y, Kurosaki T, Madesh M, et al. 2010. S-glutathionylation activates STIM1 and alters mitochondrial homeostasis. J Cell Biol 190: 391-405.

Hofer AM, Fasolato C, Pozzan T. 1998. Capacitative $\mathrm{Ca}^{2+}$ entry is closely linked to the filling state of internal $\mathrm{Ca}^{2+}$ stores: A study using simultaneous measurements of $\mathrm{I}_{\mathrm{CRAC}}$ and intraluminal $\left[\mathrm{Ca}^{2+}\right]$. J Cell Biol 140: 325334.

Hogan PG, Lewis RS, Rao A. 2010. Molecular basis of calcium signaling in lymphocytes: STIM and ORAI. Annu Rev Immunol 28: 491-533.

Honnappa S, Gouveia SM, Weisbrich A, Damberger FF, Bhavesh NS, Jawhari H, Grigoriev I, van Rijssel, Buey RM, Lawera A, Steinmetz MO, et al. 2009. An EB1-binding motif acts as a microtubule tip localization signal. Cell 138: $366-376$.

Hoover PJ, Lewis RS. 2011. Stoichiometric requirements for trapping and gating of CRAC channels by stromal interaction molecule 1 (STIM1). Proc Natl Acad Sci doi: 10.1073/pnas.1101664108.

Hoth M. 1995. Calcium and barium permeation through calcium release-activated calcium (CRAC) channels. Pflugers Archiv Eur J Physiol 430: 315-322.

Hoth M, Penner R. 1992. Depletion of intracellular calcium stores activates a calcium current in mast cells. Nature 355: 353-356.

Hoth M, Penner R. 1993. Calcium release-activated calcium current in rat mast cells. J Physiol 465: 359-386.

Huang G, Zeng W, Kim J, Yuan J, Han L, Muallem S, Worley P. 2006. STIM1 carboxyl-terminus activates native SOC $I_{\text {crac }}$ and TRPC1 channels. Nat Cell Biol 8: 1003-1010.

Ji W, Xu P, Li Z, Lu J, Liu L, Zhan Y, Chen Y, Hille B, Xu T, Chen L. 2008. Functional stoichiometry of the unitary calcium-release-activated calcium channel. Proc Natl Acad Sci 105: 13668-13673.

Kar P, Nelson C, Parekh AB. 2011. Selective activation of the transcription factor NFAT1 by calcium microdomains near CRAC channels. J Biol Chem 286: 14795-14803.

Kawasaki T, Lange I, Feske S. 2009. A minimal regulatory domain in the $\mathrm{C}$ terminus of STIM1 binds to and activates ORAI1 CRAC channels. Biochem Biophys Res Commun 385: 49-54.

Korzeniowski M, Popovic M, Szentpetery Z, Varnai P, Stojilkovic S, Balla T. 2009. Dependence of stim1/orail mediated calcium entry on plasma membrane phosphoinositides. J Biol Chem 284: 21027-21035.

Korzeniowski MK, Manjarrés IM, Varnai P, Balla T. 2010. Activation of STIM1-Orail involves an intramolecular switching mechanism. Sci Signal 3: ra82.

Launikonis BS, Ríos E. 2007. Store-operated $\mathrm{Ca}^{2+}$ entry during intracellular $\mathrm{Ca}^{2+}$ release in mammalian skeletal muscle. J Physiol 583: 81-97. 
Launikonis BS, Murphy RM, Edwards JN. 2010. Toward the roles of store-operated $\mathrm{Ca}^{2+}$ entry in skeletal muscle. Pflugers Arch 460: 813-823.

Lee KP, Yuan JP, Zeng W, So I, Worley PF, Muallem S. 2009. Molecular determinants of fast $\mathrm{Ca}^{2+}$-dependent inactivation and gating of the Orai channels. Proc Natl Acad Sci 106: $14687-14692$.

Lewis RS, Cahalan MD. 1989. Mitogen-induced oscillations of cytosolic $\mathrm{Ca}^{2+}$ and transmembrane $\mathrm{Ca}^{2+}$ current in human leukemic T cells. Cell Regul 1: 99-112.

Li Z, Lu J, Xu P, Xie X, Chen L, Xu T. 2007. Mapping the interacting domains of STIM1 and Orail in $\mathrm{Ca}^{2+}$ release-activated $\mathrm{Ca}^{2+}$ channel activation. J Biol Chem 282: $29448-29456$.

Li Z, Liu L, Deng Y, Ji W, Du W, Xu P, Chen L, Xu T. 2011. Graded activation of CRAC channel by binding of different numbers of STIM1 to Orail subunits. Cell Res 21: 305-315.

Liou J, Kim M, Heo W, Jones J, Myers J, Ferrell J, Meyer T. 2005. STIM is a $\mathrm{Ca}^{2+}$ sensor essential for $\mathrm{Ca}^{2+}$-storedepletion-triggered $\mathrm{Ca}^{2+}$ influx. Curr Biol 15: $1235-$ 1241.

Liou J, Fivaz M, Inoue T, Meyer T. 2007. Live-cell imaging reveals sequential oligomerization and local plasma membrane targeting of stromal interaction molecule 1 after $\mathrm{Ca}^{2+}$ store depletion. Proc Natl Acad Sci 104: 9301-9306.

Lioudyno M, Kozak J, Penna A, Safrina O, Zhang S, Sen D, Roos J, Stauderman K, Cahalan M. 2008. Orail and STIM1 move to the immunological synapse and are up-regulated during T cell activation. Proc Natl Acad Sci 105: 2011-2016.

Lis A, Peinelt C, Beck A, Parvez S, Monteilh-Zoller M, Fleig A, Penner R. 2007. CRACM1, CRACM2, and CRACM3 are store-operated $\mathrm{Ca}^{2+}$ channels with distinct functional properties. Curr Biol 17: 794-800.

Lis A, Zierler S, Peinelt C, Fleig A, Penner R. 2010. A single lysine in the N-terminal region of store-operated channels is critical for STIM1-mediated gating. J Gen Physiol 136: $673-686$.

Litjens T, Harland M, Roberts M, Barritt G, Rychkov G. 2004. Fast $\mathrm{Ca}^{2+}$-dependent inactivation of the storeoperated $\mathrm{Ca}^{2+}$ current ( $\mathrm{I}_{\mathrm{SOC}}$ ) in liver cells: A role for calmodulin. J Physiol 558: 85-97.

Luik R, Wu M, Buchanan J, Lewis R. 2006. The elementary unit of store-operated $\mathrm{Ca}^{2+}$ entry: Local activation of CRAC channels by STIM1 at ER-plasma membrane junctions. J Cell Biol 174: 815-825.

Luik R, Wang B, Prakriya M, Wu M, Lewis R. 2008. Oligomerization of STIM1 couples ER calcium depletion to CRAC channel activation. Nature 454: 538-542.

Lur G, Haynes L, Prior I, Gerasimenko O, Feske S, Petersen O, Burgoyne R, Tepikin A. 2009. Ribosome-free Terminals of Rough ER Allow Formation of STIM1 Puncta and Segregation of STIM1 from $\mathrm{IP}_{3}$ Receptors. Curr Biol 19: 1648-1653.

Madl J, Weghuber J, Fritsch R, Derler I, Fahrner M, Frischauf I, Lackner B, Romanin C, Schütz GJ. 2010. Resting-state Orail diffuses as homotetramer in the plasma membrane of live mammalian cells. J Biol Chem 285: 41135-41142.
Malli R, Naghdi S, Romanin C, Graier WF. 2008. Cytosolic $\mathrm{Ca}^{2+}$ prevents the subplasmalemmal clustering of STIM1: An intrinsic mechanism to avoid $\mathrm{Ca}^{2+}$ overload. J Cell Sci 121: 3133-3139.

Manji S, Parker N, Williams R, van Stekelenburg L, Pearson R, Dziadek M, Smith P. 2000. STIM1: A novel phosphoprotein located at the cell surface. Biochim Biophys Acta 1481: 147-155.

Mason MJ, Mahaut-Smith MP, Grinstein S. 1991. The role of intracellular $\mathrm{Ca}^{2+}$ in the regulation of the plasma membrane $\mathrm{Ca}^{2+}$ permeability of unstimulated rat lymphocytes. J Biol Chem 266: 10872-10879.

Matsumoto M, Fujii Y, Baba A, Hikida M, Kurosaki T, Baba Y. 2011. The calcium sensors STIM1 and STIM2 control $\mathrm{B}$ cell regulatory function through interleukin-10 production. Immunity 34: 703-714.

McCarl C-A, Picard C, Khalil S, Kawasaki T, Röther J, Papolos A, Kutok J, Hivroz C, LeDeist F, Plogmann K, Ehl S, Feske S, et al. 2009. ORAI1 deficiency and lack of storeoperated $\mathrm{Ca}^{2+}$ entry cause immunodeficiency, myopathy, and ectodermal dysplasia. J Allergy Clin Immunol 124: 1311-1318.e7.

McNally BA, Yamashita M, Engh A, Prakriya M. 2009. Structural determinants of ion permeation in CRAC channels. Proc Natl Acad Sci 106: 22516-22521.

Mercer J, Dehaven W, Smyth J, Wedel B, Boyles R, Bird G, Putney J. 2006. Large store-operated calcium selective currents due to co-expression of Orail or Orai2 with the intracellular calcium sensor, Stim1. J Biol Chem 281: 24979-24990.

Mignen O, Thompson JL, Shuttleworth TJ. 2007. STIM1 regulates $\mathrm{Ca}^{2+}$ entry via arachidonate-regulated $\mathrm{Ca}^{2+}$ selective (ARC) channels without store depletion or translocation to the plasma membrane. J Physiol (Lond) 579: 703-715.

Mignen O, Thompson JL, Shuttleworth TJ. 2008. Orail subunit stoichiometry of the mammalian CRAC channel pore. J Physiol (Lond) 586: 419-425.

Mignen O, Thompson JL, Shuttleworth TJ. 2009. The molecular architecture of the arachidonate-regulated $\mathrm{Ca}^{2+}$-selective ARC channel is a pentameric assembly of Orai1 and Orai3 subunits. J Physiol 587: 4181-4197.

Muik M, Frischauf I, Derler I, Fahrner M, Bergsmann J, Eder P, Schindl R, Hesch C, Polzinger B, Fritsch R, Romanin C, et al. 2008. Dynamic coupling of the putative coiled-coil domain of ORAI1 with STIM1 mediates ORAI1 channel activation. J Biol Chem 283: 8014-8022.

Muik M, Fahrner M, Derler I, Schindl R, Bergsmann J, Frischauf I, Groschner K, Romanin C. 2009. A cytosolic homomerization and a modulatory domain within STIM1 C terminus determine coupling to ORAIl channels. J Biol Chem 284: 8421-8426.

Muik M, Fahrner M, Schindl R, Stathopulos P, Frischauf I, Derler I, Plenk P, Lackner B, Groschner K, Ikura M, Romanin C. 2011. STIM1 couples to ORAI1 via an intramolecular transition into an extended conformation. EMBO J 30: 1678-1689.

Mullins F, Park C, Dolmetsch R, Lewis R. 2009. STIM1 and calmodulin interact with Orail to induce $\mathrm{Ca}^{2+}$-dependent inactivation of CRAC channels. Proc Natl Acad Sci 106: $15495-15500$. 


\section{R.S. Lewis}

Navarro-Borelly L, Somasundaram A, Yamashita M, Ren D, Miller RJ, Prakriya M. 2008. STIM1-Orail interactions and Orail conformational changes revealed by live-cell FRET microscopy. J Physiol 586: 5383-5401.

Ng S-W, Nelson C, Parekh AB. 2009. Coupling of $\mathrm{Ca}^{2+}$ microdomains to spatially and temporally distinct cellular responses by the tyrosine kinase Syk. J Biol Chem 284: 24767-24772.

Oh-Hora M. 2009. Calcium signaling in the development and function of T-lineage cells. Immunol Rev 231: 210 224.

Oh-Hora M, Yamashita M, Hogan P, Sharma S, Lamperti E, Chung W, Prakriya M, Feske S, Rao A. 2008. Dual functions for the endoplasmic reticulum calcium sensors STIM1 and STIM2 in T cell activation and tolerance. Nat Immunol 9: 432-443.

Orci L, Ravazzola M, Le Coadic M, Shen W-W, Demaurex N Cosson P. 2009. STIM1-induced precortical and cortical subdomains of the endoplasmic reticulum. Proc Natl Acad Sci 106: $19358-19362$

Pan Z, Yang D, Nagaraj RY, Nosek TA, Nishi M, Takeshima H, Cheng H, Ma J. 2002. Dysfunction of store-operated calcium channel in muscle cells lacking mg29. Nat Cell Biol 4: 379-383.

Parekh AB, Penner R. 1997. Store depletion and calcium influx. Physiol Rev 77: 901-930.

Parekh AB, Putney JW. 2005. Store-operated calcium channels. Physiol Rev 85: 757-810.

Park CY, Hoover PJ, Mullins FM, Bachhawat P, Covington ED, Raunser S, Walz T, Garcia KC, Dolmetsch RE, Lewis RS. 2009. STIM1 clusters and activates CRAC channels via direct binding of a cytosolic domain to Orail. Cell 136: $876-890$.

Park CY, Shcheglovitov A, Dolmetsch R. 2010. The CRAC channel activator STIM1 binds and inhibits L-type voltage-gated calcium channels. Science 330: 101-105.

Partiseti M, Le Deist F, Hivroz C, Fischer A, Korn H, Choquet D. 1994. The calcium current activated by $\mathrm{T}$ cell receptor and store depletion in human lymphocytes is absent in a primary immunodeficiency. J Biol Chem 269: 32327-32335.

Peinelt C, Vig M, Koomoa D, Beck A, Nadler M, KoblanHuberson M, Lis A, Fleig A, Penner R, Kinet J. 2006. Amplification of CRAC current by STIM1 and CRACM1 (Orai1). Nat Cell Biol 8: 771-773.

Penna A, Demuro A, Yeromin AV, Zhang SL, Safrina O, Parker I, Cahalan MD. 2008. The CRAC channel consists of a tetramer formed by Stim-induced dimerization of Orai dimers. Nature 456: 116-120.

Penner R, Matthews G, Neher E. 1988. Regulation of calcium influx by second messengers in rat mast cells. Nature 334: 499-504.

Picard C, McCarl C-A, Papolos A, Khalil S, Lüthy K, Hivroz C, LeDeist F, Rieux-Laucat F, Rechavi G, Rao A, Fischer A, Feske S. 2009. STIM1 mutation associated with a syndrome of immunodeficiency and autoimmunity. $N$ Engl J Med 360: 1971-1980.

Pozo-Guisado E, Campbell DG, Deak M, AlvarezBarrientos A, Morrice NA, Alvarez IS, Alessi DR, MartínRomero FJ. 2010. Phosphorylation of STIM1 at ERK1/2 target sites modulates store-operated calcium entry. J Cell Sci 123: 3084-3093.

Prakriya M, Lewis R. 2006. Regulation of CRAC channel activity by recruitment of silent channels to a high openprobability gating mode. J Gen Physiol 128: 373-386.

Prakriya M, Lewis R, Maue R, Bittar E. 2004. Store-operated calcium channels: Properties, functions and the search for a molecular mechanism. Adv Molec Cell Biol 32: $121-140$.

Prakriya M, Feske S, Gwack Y, Srikanth S, Rao A, Hogan P. 2006. Orail is an essential pore subunit of the CRAC channel. Nature 443: 230-233.

Putney JW. 1986. A model for receptor-regulated calcium entry. Cell Calcium 7: 1-12.

Putney JW. 2009. Capacitative calcium entry: From concept to molecules. Immunol Rev 231: 10-22.

Putney JW, Bird GS. 1993. The inositol phosphate-calcium signaling system in nonexcitable cells. Endocr Rev 14: 610-631.

Roos J, DiGregorio P, Yeromin A, Ohlsen K, Lioudyno M, Zhang S, Safrina O, Kozak J, Wagner S, Cahalan M, Stauderman K, et al. 2005. STIM1, an essential and conserved component of store-operated $\mathrm{Ca}^{2+}$ channel function. J Cell Biol 169: 435-445.

Sarkadi B, Tordai A, Homolya L, Scharff O, Gárdos G. 1991. Calcium influx and intracellular calcium release in antiCD3 antibody-stimulated and thapsigargin-treated human T lymphoblasts. J Membr Biol 123: 9-21.

Scrimgeour N, Litjens T, Ma L, Barritt GJ, Rychkov GY. 2009. Properties of Orail mediated store-operated current depend on the expression levels of STIM1 and Orail proteins. J Physiol 587: 2903-2918.

Shuttleworth TJ. 2009. Arachidonic acid, ARC channels, and Orai proteins. Cell Calcium 45: 602-610.

Singaravelu K, Nelson C, Bakowski D, Martins de Brito O, Ng SW, Di Capite J, Powell T, Scorrano L, Parekh AB. 2011. Mitofusin 2 regulates STIM1 migration from the $\mathrm{Ca}^{2+}$ store to the plasma membrane in cells with depolarised mitochondria. J Biol Chem 286: 12189-12201.

Smyth J, Dehaven W, Bird G, Putney J. 2007. Role of the microtubule cytoskeleton in the function of the storeoperated $\mathrm{Ca}^{2+}$ channel activator STIM1. J Cell Sci 120: 3762-3771.

Smyth J, DeHaven W, Bird G, Putney J Jr. 2008. Ca ${ }^{2+}$-storedependent and -independent reversal of Stim1 localization and function. J Cell Sci 121: 762-772.

Smyth JT, Petranka JG, Boyles RR, DeHaven WI, Fukushima M, Johnson KL, Williams JG, Putney JW. 2009. Phosphorylation of STIM1 underlies suppression of storeoperated calcium entry during mitosis. Nat Cell Biol 11: 1465-1472.

Soboloff J, Spassova M, Tang X, Hewavitharana T, Xu W, Gill D. 2006. Orail and STIM reconstitute store-operated calcium channel function. J Biol Chem 281: 20661-20665.

Srikanth S, Jung H-J, Kim K-D, Souda P, Whitelegge J, Gwack Y. 2010. A novel EF-hand protein, CRACR2A, is a cytosolic $\mathrm{Ca}^{2+}$ sensor that stabilizes CRAC channels in T cells. Nat Cell Biol 12: 436-446.

Srikanth S, Jung HJ, Ribalet B, Gwack Y. 2010. The intracellular loop of Orail plays a central role in fast inactivation 
of $\mathrm{Ca}^{2+}$ release-activated $\mathrm{Ca}^{2+}$ channels. J Biol Chem 285: 5066-5075.

Stathopulos P, Li G, Plevin M, Ames J, Ikura M. 2006. Stored $\mathrm{Ca}^{2+}$ depletion-induced oligomerization of STIM1 via the EF-SAM region: An initiation mechanism for capacitive $\mathrm{Ca}^{2+}$ entry. J Biol Chem 281: 35855-35862.

Stathopulos PB, Zheng L, Li G-Y, Plevin MJ, Ikura M. 2008. Structural and mechanistic insights into STIM1-mediated initiation of store-operated calcium entry. Cell 135: $110-122$.

Stemmer, Paul M, Klee, Claude B. 1994. Dual calcium ion regulation of calcineurin by calmodulin and calcineurin B. Biochemistry 33: 6859-6866.

Stiber J, Hawkins A, Wang S, Burch J, Graham V, Ward CC, Seth M, Finch E, Malouf N, Williams RS, Rosenberg P, et al. 2008. STIM1 signalling controls store-operated calcium entry required for development and contractile function in skeletal muscle. Nat Cell Biol 10: 688-697.

Südhof TC, Rothman JE. 2009. Membrane fusion: Grappling with SNARE and SM proteins. Science 323: 474477.

Thastrup O, Dawson AP, Scharff O, Foder B, Cullen PJ, Drøbak BK, Bjerrum PJ, Christensen SB, Hanley MR 1989. Thapsigargin, a novel molecular probe for studying intracellular calcium release and storage. Agents Actions 27: 17-23.

Thompson J, Mignen O, Shuttleworth TJ. 2010. The $\mathrm{N}$-terminal domain of Orai3 determines selectivity for activation of the store-independent ARC channel by arachidonic acid. Channels (Austin) 4: 398-410.

Treves S, Franzini-Armstrong C, Moccagatta L, Arnoult C, Grasso C, Schrum A, Ducreux S, Zhu MX, Mikoshiba K, Girard T, Zorzato F, et al. 2004. Junctate is a key element in calcium entry induced by activation of $\mathrm{InsP}_{3}$ receptors and/or calcium store depletion. J Cell Biol 166: $537-548$.

Treves S, Vukcevic M, Griesser J, Armstrong CF, Zhu MX, Zorzato F. 2010. Agonist-activated $\mathrm{Ca}^{2+}$ influx occurs at stable plasma membrane and endoplasmic reticulum junctions. J Cell Sci 123: 4170-4181.

Varga-Szabo D, Braun A, Kleinschnitz C, Bender M, Pleines I, Pham M, Renné T, Stoll G, Nieswandt B. 2008. The calcium sensor STIM1 is an essential mediator of arterial thrombosis and ischemic brain infarction. J Exp Med 205: $1583-1591$.

Varga-Szabo D, Braun A, Nieswandt B. 2009. Calcium signaling in platelets. J Thromb Haemost 7: 1057-1066.

Várnai P, Tóth B, Tóth DJ, Hunyady L, Balla T. 2007. Visualization and manipulation of plasma membrane-endoplasmic reticulum contact sites indicates the presence of additional molecular components within the STIM1Orail Complex. J Biol Chem 282: 29678-29690.

Várnai P, Hunyady L, Balla T. 2009. STIM and Orai: The long-awaited constituents of store-operated calcium entry. Trends Pharmacol Sci 30: 118-128.

Vig M, Kinet J-P. 2009. Calcium signaling in immune cells. Nat Immunol 10: 21-27.

Vig M, Beck A, Billingsley J, Lis A, Parvez S, Peinelt C, Koomoa D, Soboloff J, Gill D, Fleig A, Penner R, et al. 2006a. CRACM1 multimers form the ion-selective pore of the CRAC channel. Curr Biol 16: 2073-2079.
Vig M, Peinelt C, Beck A, Koomoa DL, Rabah D, KoblanHuberson M, Kraft S, Turner H, Fleig A, Penner R, Kinet J-P. 2006b. CRACM1 is a plasma membrane protein essential for store-operated $\mathrm{Ca}^{2+}$ entry. Science 312: $1220-1223$.

Vig M, DeHaven W, Bird G, Billingsley J, Wang H, Rao P, Hutchings A, Jouvin M, Putney J, Kinet J. 2008. Defective mast cell effector functions in mice lacking the CRACM1 pore subunit of store-operated calcium release-activated calcium channels. Nat Immunol 9: 89-96.

Walsh CM, Chvanov M, Haynes LP, Petersen OH, Tepikin AV, Burgoyne RD. 2010a. Role of phosphoinositides in STIM1 dynamics and store-operated calcium entry. Biochem J 425: 159-168.

Walsh CM, Doherty MK, Tepikin AV, Burgoyne RD. 2010b. Evidence for an interaction between Golli and STIM1 in store-operated calcium entry. Biochem J 430: 453-460.

Wang Y, Deng X, Mancarella S, Hendron E, Eguchi S, Soboloff J, Tang XD, Gill DL. 2010. The calcium store sensor, STIM1, reciprocally controls Orai and $\mathrm{Ca}_{\mathrm{V}} 1.2$ channels. Science 330: 105-109.

Williams R, Manji S, Parker N, Hancock M, Van Stekelenburg L, Eid J, Senior P, Kazenwadel J, Shandala T, Saint R. 2001. Identification and characterization of the STIM (stromal interaction molecule) gene family: Coding for a novel class of transmembrane proteins. Biochem J 357: 673-685.

Willoughby D, Cooper DMF. 2007. Organization and $\mathrm{Ca}^{2+}$ regulation of adenylyl cyclases in cAMP microdomains. Physiol Rev 87: 965-1010.

Woodard GE, Salido GM, Rosado JA. 2008. Enhanced exocytotic-like insertion of Orail into the plasma membrane upon intracellular $\mathrm{Ca}^{2+}$ store depletion. Am J Physiol, Cell Physiol 294: C1323-C1331.

Wu M, Buchanan J, Luik R, Lewis R. 2006. $\mathrm{Ca}^{2+}$ store depletion causes STIM1 to accumulate in ER regions closely associated with the plasma membrane. J Cell Biol 174: 803-813.

Wu M, Luik R, Lewis R. 2007. Some assembly required: Constructing the elementary units of store-operated $\mathrm{Ca}^{2+}$ entry. Cell Calcium 42: 163-172.

Xiao B, Coste B, Mathur J, Patapoutian A. 2011. Temperature-dependent STIM1 activation induces $\mathrm{Ca}^{2+}$ influx and modulates gene expression. Nat Chem Biol 7: 351358.

Xu P, Lu J, Li Z, Yu X, Chen L, Xu T. 2006. Aggregation of STIM1 underneath the plasma membrane induces clustering of Orail. Biochem Biophys Res Commun 350: 969-976.

Yamashita M, Navarro-Borelly L, McNally B, Prakriya M. 2007. Orail mutations alter ion permeation and $\mathrm{Ca}^{2+}$. dependent fast inactivation of CRAC channels: Evidence for coupling of permeation and gating. J Gen Physiol 130: $525-540$.

Yeromin A, Zhang S, Jiang W, Yu Y, Safrina O, Cahalan M. 2006. Molecular identification of the CRAC channel by altered ion selectivity in a mutant of Orai. Nature 443: 226-229.

Yu F, Sun L, Machaca K. 2009. Orail internalization and STIM1 clustering inhibition modulate SOCE inactivation during meiosis. Proc Natl Acad Sci 106: 1740117406. 


\section{R.S. Lewis}

Yu F, Sun L, Machaca K. 2010. Constitutive recycling of the store-operated $\mathrm{Ca}^{2+}$ channel Orail and its internalization during meiosis. J Cell Biol 191: 523-535.

Yuan J, Zeng W, Dorwart M, Choi Y, Worley P, Muallem S. 2009. SOAR and the polybasic STIM1 domains gate and regulate Orai channels. Nat Cell Biol 11: 337-343.

Zeng W, Yuan JP, Kim MS, Choi YJ, Huang GN, Worley PF, Muallem S. 2008. STIM1 gates TRPC channels, but not Orai1, by electrostatic interaction. Mol Cell 32: 439-448.

Zhang S, Yu Y, Roos J, Kozak J, Deerinck T, Ellisman M, Stauderman K, Cahalan M. 2005. STIM1 is a $\mathrm{Ca}^{2+}$ sensor that activates CRAC channels and migrates from the $\mathrm{Ca}^{2+}$ store to the plasma membrane. Nature 437: 902-905.

Zhang SL, Yeromin AV, Zhang XH-F, Yu Y, Safrina O, Penna A, Roos J, Stauderman KA, Cahalan MD. 2006. Genomewide RNAi screen of $\mathrm{Ca}^{2+}$ influx identifies genes that regulate $\mathrm{Ca}^{2+}$ release-activated $\mathrm{Ca}^{2+}$ channel activity. Proc Natl Acad Sci 103: 9357-9362.

Zhou Y, Meraner P, Kwon HT, Machnes D, Masatsugu O-H, Zimmer J, Huang Y, Stura A, Rao A, Hogan PG. 2010a. STIM1 gates the store-operated calcium channel ORAI1 in vitro. Nat Struct Mol Biol 17: 112-116.

Zhou Y, Ramachandran S, Oh-hora M, Rao A, Hogan PG. 2010b. Pore architecture of the ORAI1 store-operated calcium channel. Proc Natl Acad Sci 107: 4896-4901.

Zweifach A, Lewis RS. 1993. Mitogen-regulated $\mathrm{Ca}^{2+}$ current of T lymphocytes is activated by depletion of intracellular $\mathrm{Ca}^{2+}$ stores. Proc Natl Acad Sci 90: 62956299.

Zweifach A, Lewis RS. 1995. Rapid inactivation of depletion-activated calcium current $\left(I_{\mathrm{CRAC}}\right)$ due to local calcium feedback. J Gen Physiol 105: 209-226. 


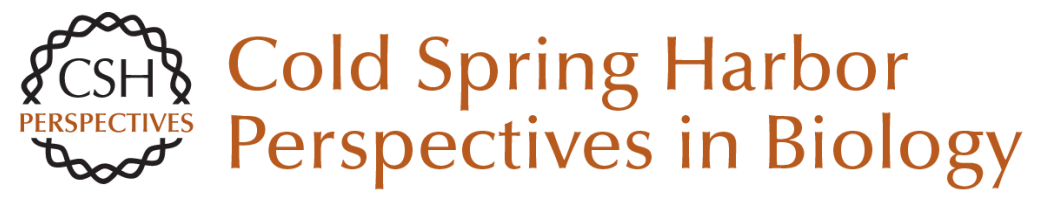

\section{Store-Operated Calcium Channels: New Perspectives on Mechanism and Function}

Richard S. Lewis

Cold Spring Harb Perspect Biol 2011; doi: 10.1101/cshperspect.a003970 originally published online July 26, 2011

\section{Subject Collection Calcium Signaling}

The Endoplasmic Reticulum-Plasma Membrane Junction: A Hub for Agonist Regulation of $\mathrm{Ca}^{2+}$ Entry

Hwei Ling Ong and Indu Suresh Ambudkar

Calcium-Handling Defects and Neurodegenerative

Disease

Sean Schrank, Nikki Barrington and Grace E. Stutzmann

Lysosomal $\mathrm{Ca}^{2+}$ Homeostasis and Signaling in Health and Disease

Emyr Lloyd-Evans and Helen Waller-Evans

$\mathrm{Ca}^{2+}$ Signaling in Exocrine Cells

Malini Ahuja, Woo Young Chung, Wei-Yin Lin, et al.

Functional Consequences of Calcium-Dependent Synapse-to-Nucleus Communication: Focus on Transcription-Dependent Metabolic Plasticity Anna M. Hagenston, Hilmar Bading and Carlos Bas-Orth

Identifying New Substrates and Functions for an Old Enzyme: Calcineurin

Jagoree Roy and Martha S. Cyert

Fundamentals of Cellular Calcium Signaling: A

Primer

Martin D. Bootman and Geert Bultynck
Primary Active $\mathrm{Ca}^{2+}$ Transport Systems in Health and Disease

Jialin Chen, Aljona Sitsel, Veronick Benoy, et al.

Signaling through $\mathrm{Ca}^{2+}$ Microdomains from

Store-Operated CRAC Channels

Pradeep Barak and Anant B. Parekh

Structural Insights into the Regulation of $\mathrm{Ca}^{2+}$ /Calmodulin-Dependent Protein Kinase II (CaMKII) Moitrayee Bhattacharyya, Deepti Karandur and John Kuriyan

Store-Operated Calcium Channels: From Function to Structure and Back Again Richard S. Lewis

Bcl-2-Protein Family as Modulators of $\mathrm{IP}_{3}$

Receptors and Other Organellar $\mathrm{Ca} 2+$ Channels Hristina Ivanova, Tim Vervliet, Giovanni Monaco, et al.

Calcium Signaling in Cardiomyocyte Function Guillaume Gilbert, Kateryna Demydenko, Eef Dries, et al.

Cytosolic $\mathrm{Ca}^{2+}$ Buffers Are Inherently $\mathrm{Ca}^{2+}$ Signal Modulators Beat Schwaller

For additional articles in this collection, see http://cshperspectives.cshlp.org/cgi/collection/

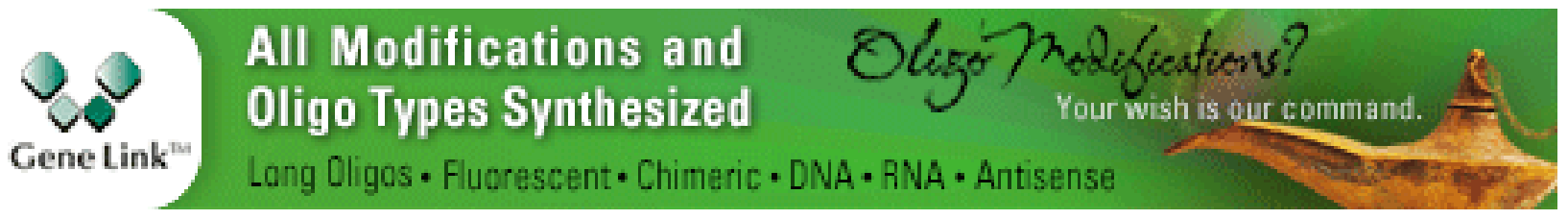


Role of Two-Pore Channels in Embryonic Development and Cellular Differentiation Sarah E. Webb, Jeffrey J. Kelu and Andrew L. Miller

\section{Organellar Calcium Handling in the Cellular \\ Reticular Network}

Wen-An Wang, Luis B. Agellon and Marek Michalak

For additional articles in this collection, see http://cshperspectives.cshlp.org/cgi/collection/

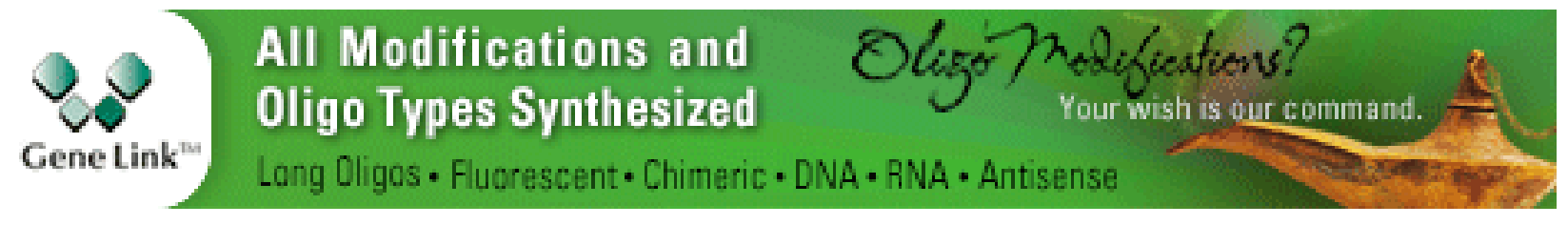

Copyright @ 2011 Cold Spring Harbor Laboratory Press; all rights reserved 